\title{
THRSP identified as a potential hepatocellular carcinoma marker by integrated bioinformatics analysis and experimental validation
}

\author{
Yuxi Ding ${ }^{1,2,3,}{ }^{*}$, Xiaoling Liu ${ }^{1,2,3,}{ }^{*}$, Yue Yuan ${ }^{1,2,3}$, Yunjian Sheng ${ }^{1,2,3}$, Decheng $\mathbf{L i}^{1,2,3}$, \\ Suvash Chandra Ojha ${ }^{1,2,3}$, Changfeng Sun ${ }^{1,2,3}$, Cunliang Deng ${ }^{1,2,3}$ \\ ${ }^{1}$ The Department of Infectious Diseases, The Affiliated Hospital of Southwest Medical University, Luzhou 646000, \\ China \\ ${ }^{2}$ The Department of Tuberculosis, The Affiliated Hospital of Southwest Medical University, Luzhou 646000, China \\ ${ }^{3}$ Laboratory of Infection and Immunity, The Affiliated Hospital of Southwest Medical University, Luzhou 646000, \\ China \\ *Co-first author
}

Correspondence to: Changfeng Sun, Cunliang Deng; email: sun cf88@swmu.edu.cn, dengcunl@swmu.edu.cn Keywords: THRSP, hepatocellular carcinoma, prognosis, invasion, migration

Received: January 30, $2021 \quad$ Accepted: January 17, 2022

Published: February 23, 2022

Copyright: (C) 2022 Ding et al. This is an open access article distributed under the terms of the Creative Commons Attribution License (CC BY 3.0), which permits unrestricted use, distribution, and reproduction in any medium, provided the original author and source are credited.

\section{ABSTRACT}

Hepatocellular carcinoma (HCC) is the most common malignant liver tumor with high mortality and poor prognosis worldwide. This study aimed to identify hub genes and investigate the underlying molecular mechanisms in HCC progression by integrated bioinformatics analysis and experimental validation. Based on the Gene Expression Omnibus (GEO) databases and The Cancer Genome Atlas (TCGA), 12 critical differential coexpression genes were identified between tumor and normal tissues. Via survival analysis, we found higher expression of LCAT, ACSM3, IGF1, SRD5A2, THRSP and ACADS was associated with better prognoses in HCC patients. Among which, THRSP was selected for the next investigations. We found that THRSP mRNA expression was negatively correlated with its methylation and closely associated with clinical characteristics in HCC patients. Moreover, THRSP expression had a negative correlation with the infiltration levels of several immune cells (e.g., B cells and CD4+ T cells). qRT-PCR verified that THRSP was lower expressed in HCC tissues and cell lines compared with control. Silencing of THRSP promoted the migration, invasion, proliferation, and inhibited cell apoptosis of HCCLM and Huh7 cell lines. Decreased expression of THRSP promoted HCC progression by NFKB, ERK1/2, and p38 MAPK signaling pathways. In conclusion, THRSP might serve as a novel biomarker and therapeutic target of HCC.

\section{INTRODUCTION}

Primary liver cancer is one of the most frequently diagnosed malignant tumors and the third leading cause of cancer-related mortality worldwide, with an estimated 906,000 new cases and 830,000 deaths in 2020 [1]. Hepatocellular carcinoma (HCC) is the most common form of primary liver cancer (accounting for 75-85\%) [1]. Due to the lack of understanding about the complex carcinogenic mechanisms and efficient therapeutic targets, the 5-year survival rate for HCC patients remains poor [2]. Thus, there is an urgent need to seek promising targets and elaborate on the underlying molecular mechanisms involved in $\mathrm{HCC}$ progression.

The major public databases such as GEO (http://www.ncbi.nlm.nih.gov/geo/) and TCGA (https:// portal.gdc.cancer.gov/), containing gene expression profiles, provide an opportunity to screen the differentially expressed genes (DEGs) related to the carcinogenesis and development of HCC [3, 4]. The 
cancer progression is regulated by the key modulators of gene-gene interaction networks, thus the Weighted Gene Co-expression Network Analysis (WGCNA) and protein-protein interaction (PPI) network analysis have been widely used to screen co-expressed genes that drive cancers $[5,6]$.

In this study, we performed differential gene expression analysis, WGCNA, and PPI network analysis to screen crucial differential co-expression genes associated with hepatocarcinogenesis based on the GEO and TCGA databases. Via 5-year survival analysis, we found that six genes (LCAT, ACSM3, IGF1, SRD5A2, THRSP, and ACADS) were associated with the prognosis of HCC patients. THRSP (thyroid hormone-responsive, also known as Spot 14 or S14) was originally identified in 1982 owing to its significant and rapid induction by thyroid hormone and it had been reported to have great effects on the tissue-specific regulation of lipid metabolism [7, 8]. Some studies demonstrated that THRSP was relatively abundant in liver, white and brown adipose, and lactating mammary tissues and it was associated with nonalcoholic fatty liver disease [9, 10]. THRSP was strongly expressed in most lipogenic breast cancers, and high expression of THRSP predicted a high recurrence rate of primary invasive breast cancers. THRSP mediated lipogenic effects of progestin, and THRSP knockdown disrupted lipid synthesis and induced apoptosis of breast cancer cells [11]. Another study reported that over-expression of THRSP increased medium-chain fatty acids synthesis and cell proliferation, but reduced tumor metastasis [12]. However, THRSP was found to be down-regulated in HCC tissues, and the decreased expression of THRSP was associated with worse prognosis in our study. To understand the roles of THRSP in HCC progression, we further analyzed the biological function and clinical implications of THRSP via integrated bioinformatics analysis. Moreover, we performed qPCR and immunohistochemical experiments to explore the mRNA and protein expression of THRSP in HCC tissues and cells. We also did Western blotting, CCK-8, Transwell, wound scratch and flow cytometry assays to investigate the function and molecular mechanism of THRSP in HCC.

\section{RESULTS}

\section{Identification of crucial modules by WGCNA}

The "WGCNA" package was used to group genes into modules by the average linkage hierarchical clustering. In this study, the soft powers $\beta=3$ and 5 were selected as the soft-thresholding to ensure scalefree networks (Figure 1A, 1B), and 11 modules in the TCGA-LIHC (Figure 1C) and 8 modules in the GEO datasets (Figure 1D) were generated. The heatmaps (Figure 1E, 1F) of module-trait relationships were plotted to identify modules most significantly correlated with clinical features (normal and tumor). We found the brown modules in the TCGA-LIHC (containing 2057 co-expression genes) and GEO datasets (containing 2145 co-expression genes) had the highest association with tumor tissues (brown module in TCGA-LIHC: $\mathrm{r}=0.69, \mathrm{p}=7 \mathrm{e}-60$; brown module in GEO datasets: $r=0.86, p=4 e-56$ ), which were selected as modules of interest for the subsequent analysis.

\section{Identification of DEGs and differentially co- expressed genes}

After normalization of the microarrays, 2705 differentially expressed genes (DEGs) between the HCC and normal tissues from the TCGA dataset (TCGA_diff) and 567 DEGs from the GEO datasets (GEO_diff) were screened by the "limma" package in $R$. Then, a Venn diagram was performed to examine the intersection among the DEGs and co-expressed genes of key modules. As shown in Figure 2A, 60 differentially co-expressed genes were finally obtained.

\section{PPI network and hub genes}

The PPI network of the 60 differentially co-expressed genes was constructed in the STRING database (Figure 2B). As showed in Figure 2C, the core genes were extracted from the PPI network by the MCC algorithms via the CytoHubba plug-in. Meanwhile, the significant modules of the 60 differential co-expression genes were established using the MCODE plug-in in Cytoscape (Figure 2D). Combining the above two algorithms, AFP, IGF1, BCHE, ACSM3, LCAT, ACSL4, ACADS, ENO3, CYP1A2, THRSP, GSTZ1, and SRD5A2 were finally selected as hub genes. Among them, AFP and ACSL4 were up-regulated and the other 10 hub genes were down-regulated in HCC tissues (Figure 3). To evaluate the prognostic values of the hub genes in HCC patients, a 5-year survival analysis was performed by Kaplan-Meier plotter. As shown in Figure 4, higher expression of LCAT, ACSM3, IGF1, SRD5A2, THRSP, and ACADS was associated with a better 5year overall survival $(\mathrm{p}<0.05)$.

\section{THRSP was down-regulated in HCC tissues and cell lines}

To verify the expression of THRSP in HCC tissues and cell lines, the quantitative real-time PCR (qRT-PCR) and immunohistochemistry (IHC) assays were performed in this study. The results of qRT-PCR verified that THRSP mRNA expression was remarkably lower in HCC tissues 
TCGA

A

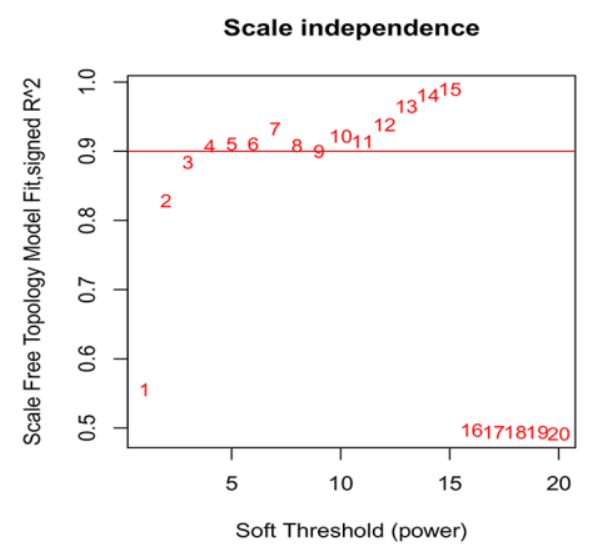

C

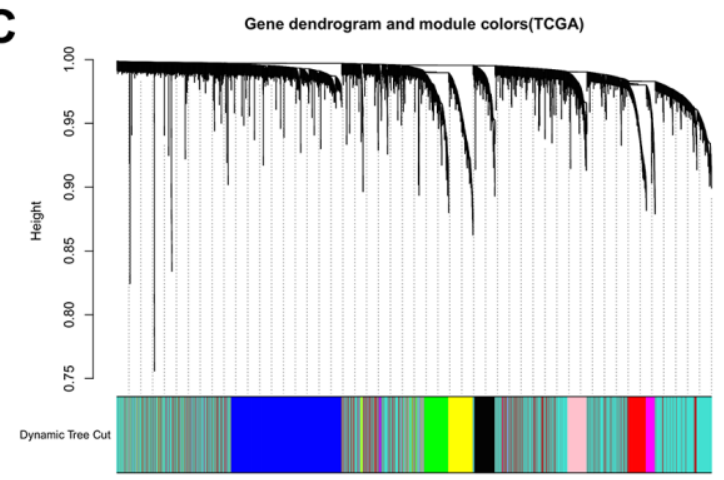

E

Module-trait relationships(TCGA)

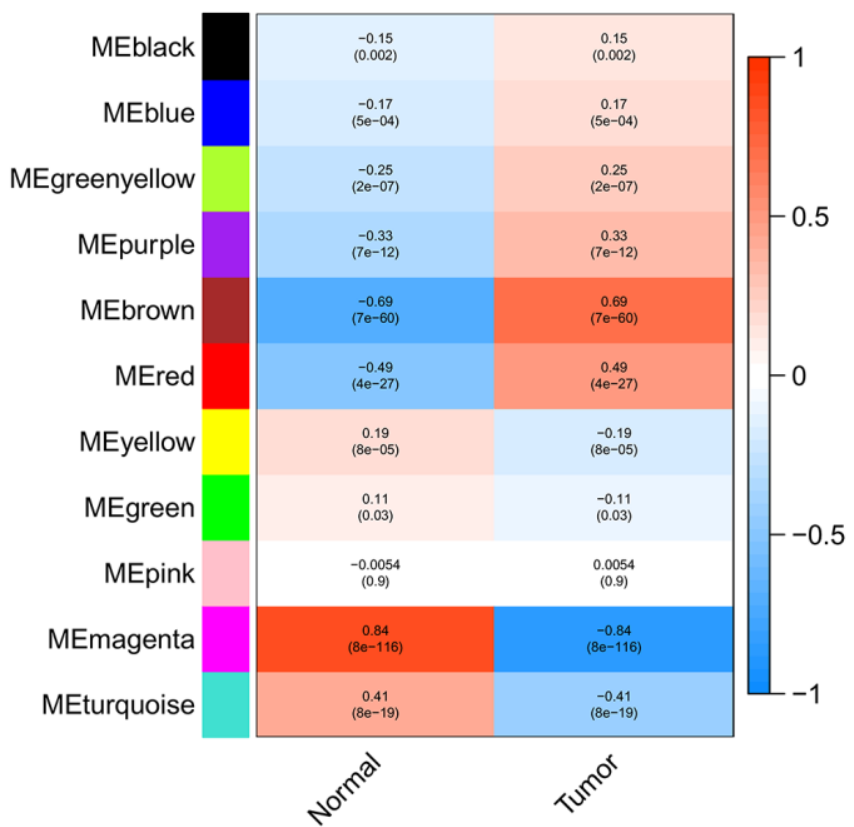

B

GEO

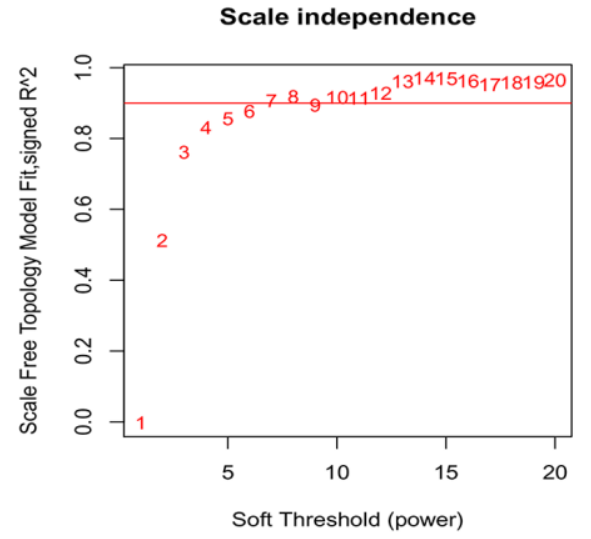

D

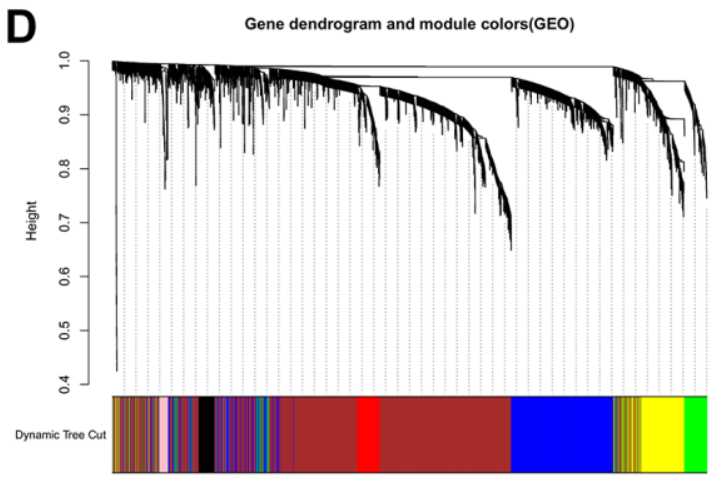

F

Module-trait relationships(GEO)

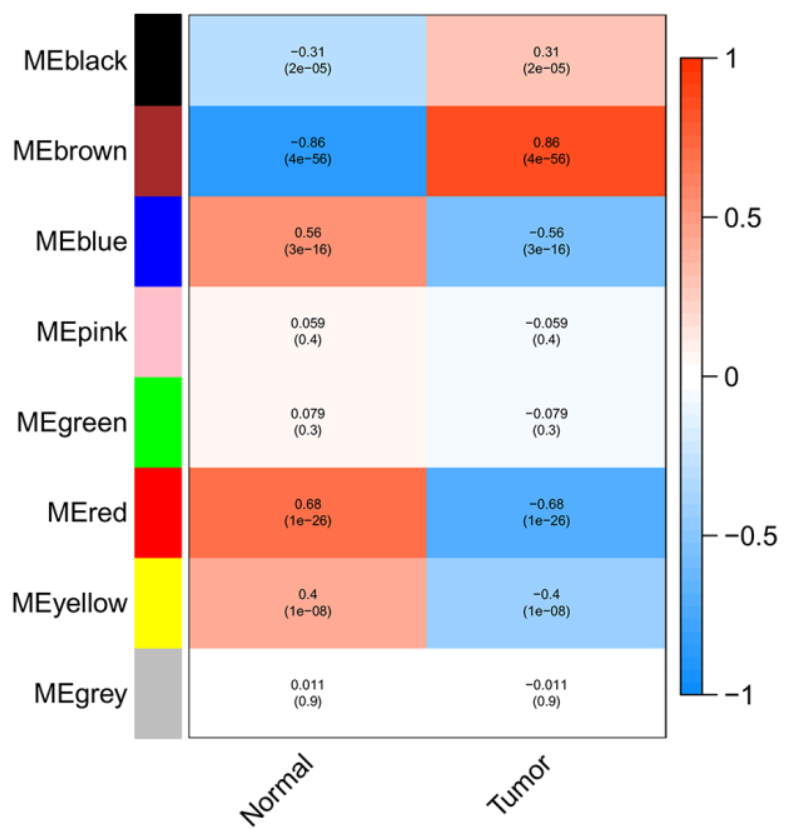

Figure 1. Identification of co-expression modules associated with the clinical traits in the TCGA-LIHC dataset and two GEO datasets. (A, B) Analysis of the scale-free fit index for various soft-thresholding powers ( $\beta$ ). (C, D) Dendrogram of all genes in the TCGA-LIHC dataset or GEO datasets clustered based on the 1-TOM matrix. (E, F) Correlation between modules and clinical traits (normal and tumor). Each cell contains the corresponding correlation coefficient (the upper number) and the P-value (the lower number). 
A

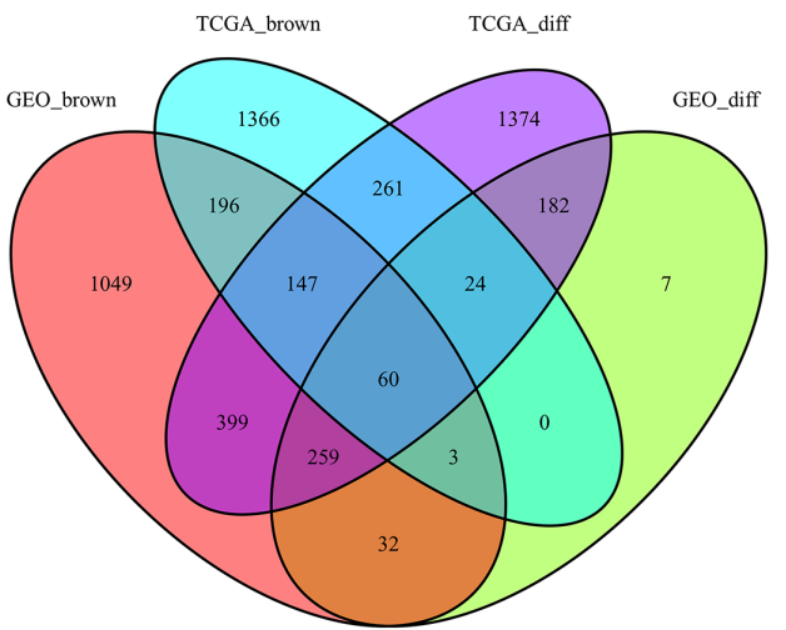

C
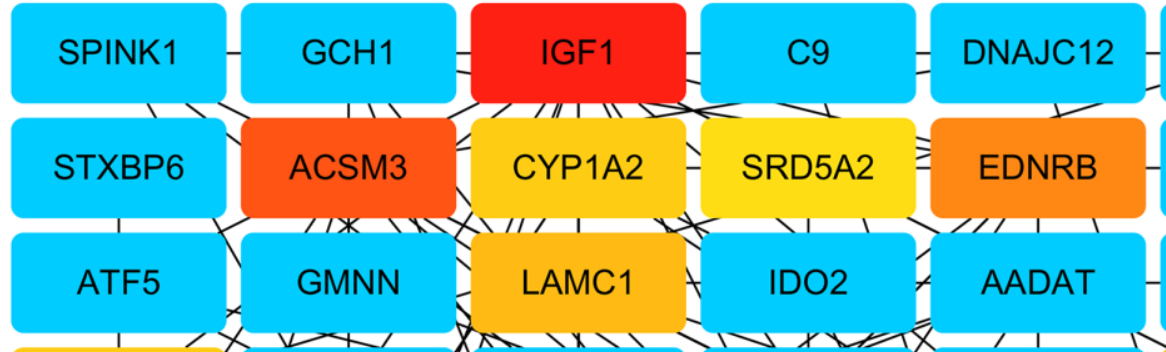

III I *
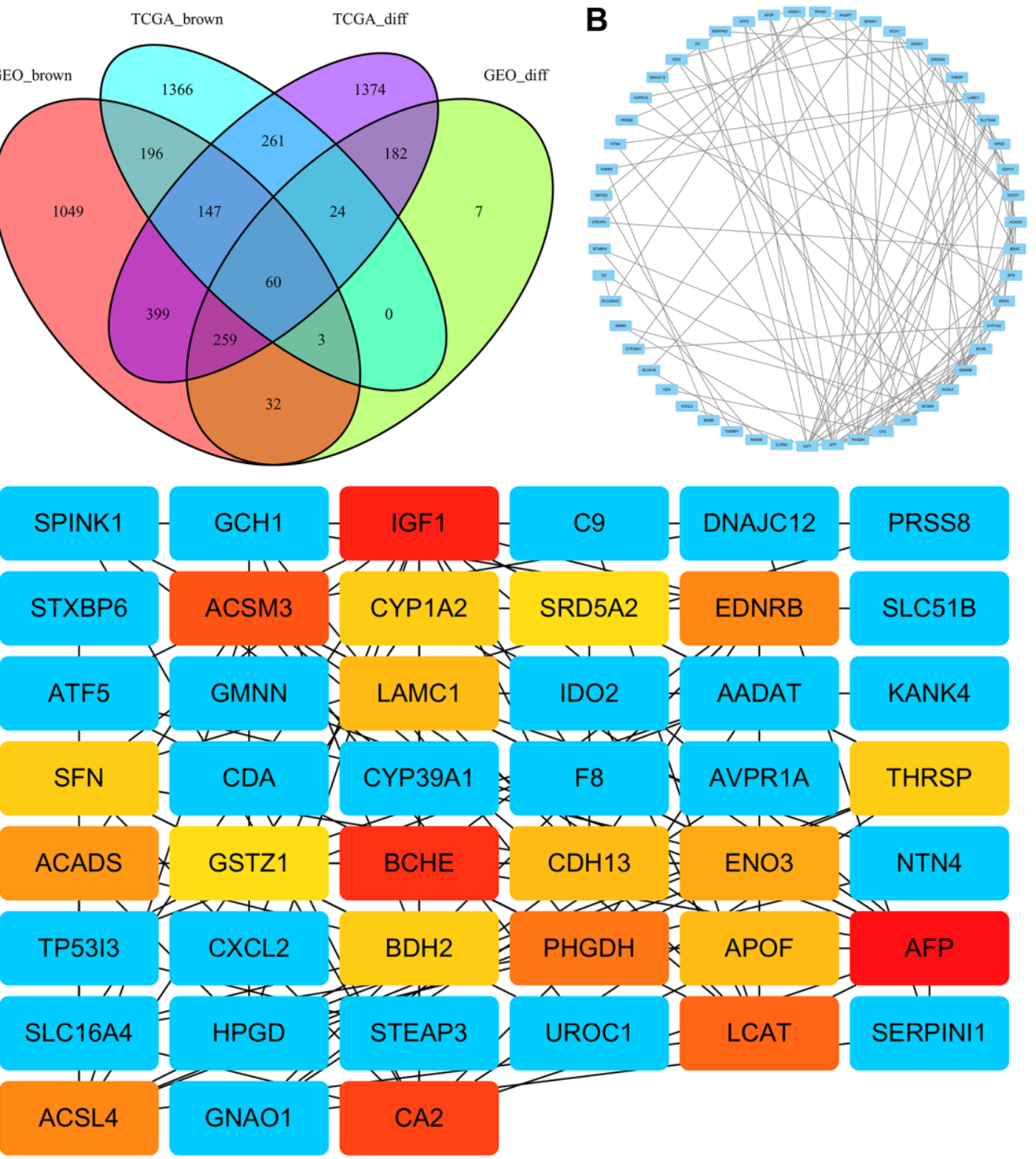

D
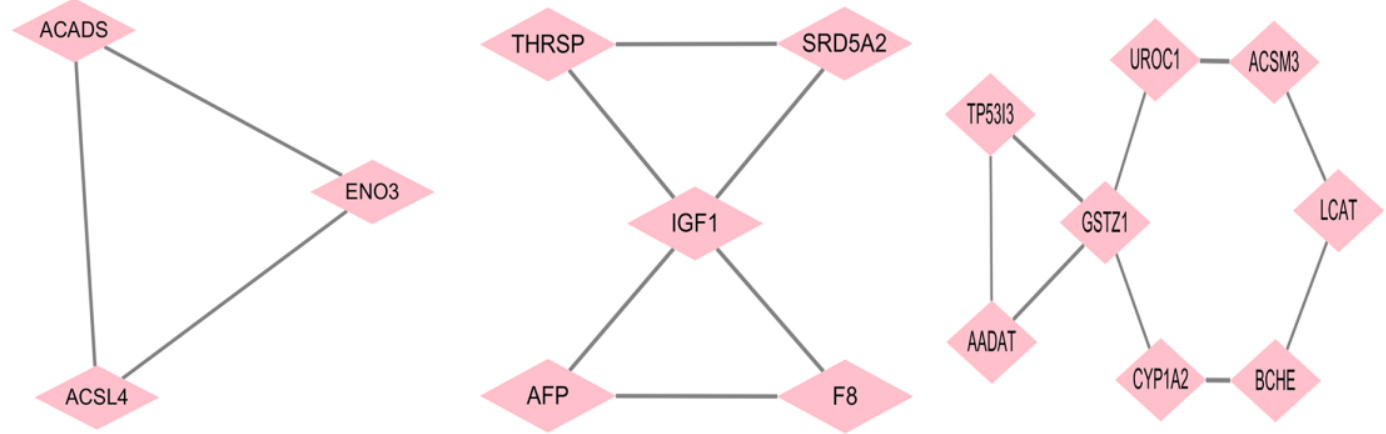

Figure 2. Identification of hub genes. (A) The Venn diagram for selection of the differential co-expression genes among DEG lists and coexpression modules. (B) PPI network of the intersection genes between DEG lists and co-expression modules. Each blue node represents a gene. Edges among nodes indicate interaction associations between genes. (C) Identification of the core genes from the PPI network by MCC algorithm. Darker colors refer to higher MCC sores. (D) The top three significant modules of the PPI network were evaluated in MOCDE. Pink nodes represent genes in corresponding modules. 

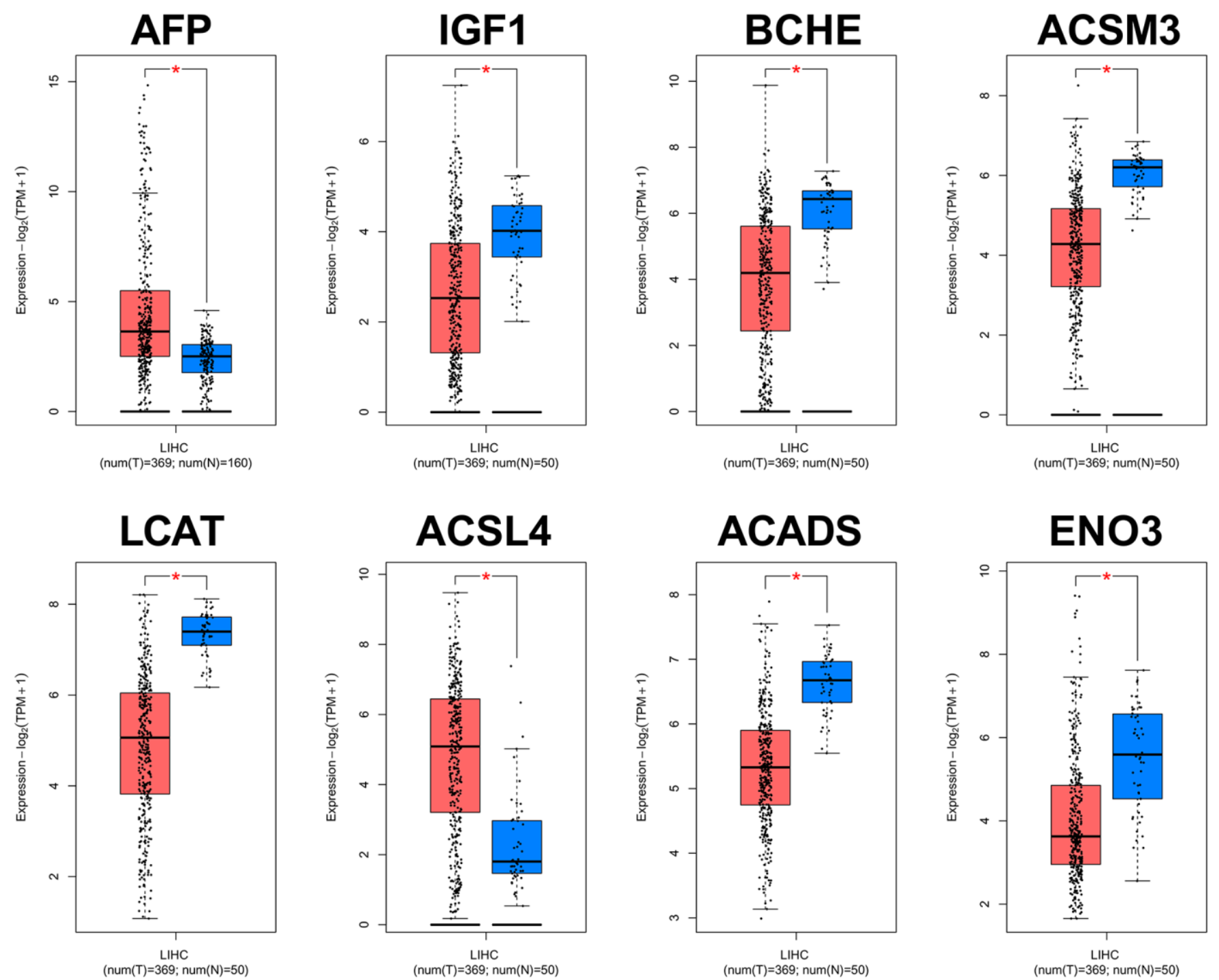

\section{ENO3}

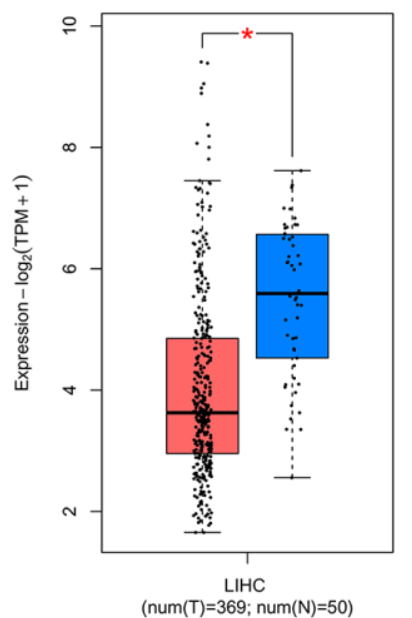

CYP1A2
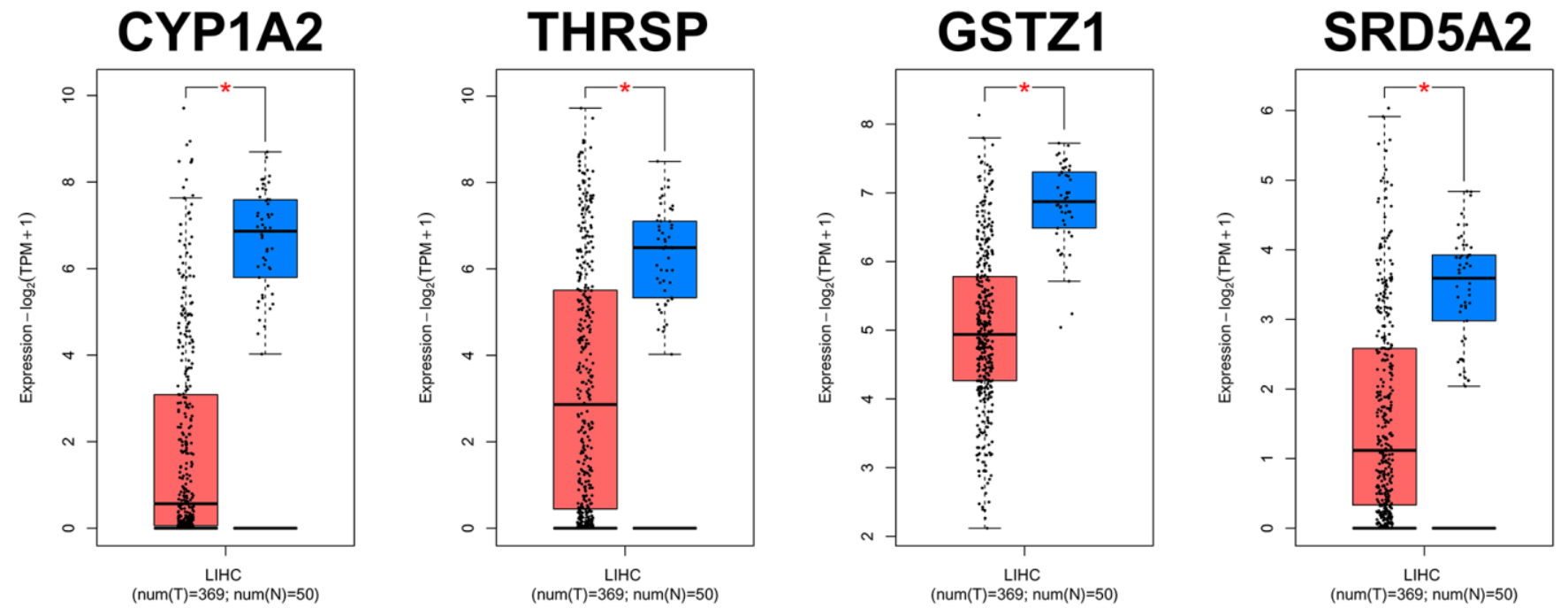

Figure 3. Validation of expression levels of the 12 hub genes in HCC and normal tissues using GEPIA. *P<0.01 is considered statistically significant. Tumor tissues are shown in red, and normal liver tissues are shown in blue. 
as well as in HCCLM3 and Huh-7 cell lines compared with normal groups (Figure 5A, 5B). The results of IHC indicated that THRSP was down-regulated in most of HCC samples (8/10) (Figure 5C).

\section{The correlation between THRSP expression and clinical characteristics}

Based on data from Illumina HumanMethylation 450 platform, we found a significant negative correlation ( $\mathrm{r}$ $=-0.81, \mathrm{p}<0.001$ ) between THRSP mRNA expression and methylation (Supplementary Figure 1A). Four THRSP promoter $\mathrm{CpG}$ sites were shown in Supplementary Figure 1B. The Spearman correlation analysis demonstrated that $\mathrm{CpG}$ sites were negatively correlated with the expression of THRSP (Supplementary Figure 1C-1F). Wilcox test was used to compare the difference in THRSP expression or methylation in groups divided by age, family history of cancer, gender, grade, Ishak fibrosis score and race. The details were shown in Supplementary Figures 2, 3. Then, the HCC patients were dichotomized into two groups ("low" or "high") based on their THRSP expression levels or THRSP methylation levels using the median values as the cutoff point. The chi-square test was used to evaluate the correlation of THRSP expression or THRSP methylation with clinical characteristics. As listed in Table 1, THRSP mRNA expression or methylation was closely associated with the clinical indicators including age, family history of cancer, Ishak fibrosis score and gender et al.

\section{Relationship of THRSP with immune infiltration based on TIMER 2.0}

As illustrated in the scatter plots (Supplementary Figure 4), THRSP expression was negatively correlated with infiltrating levels of B cells, CD4+ T cells, dendritic cells, and positively correlated with $\mathrm{CD} 8+\mathrm{T}$ cells, but was not correlated with macrophages or neutrophils. In addition, we investigated the correlations of THRSP expression with the gene markers of various immune immune-infiltrating cells (including $\mathrm{T}$ cell, $\mathrm{B}$ cell, monocyte, neutrophil, dendritic cell, tumor-associated
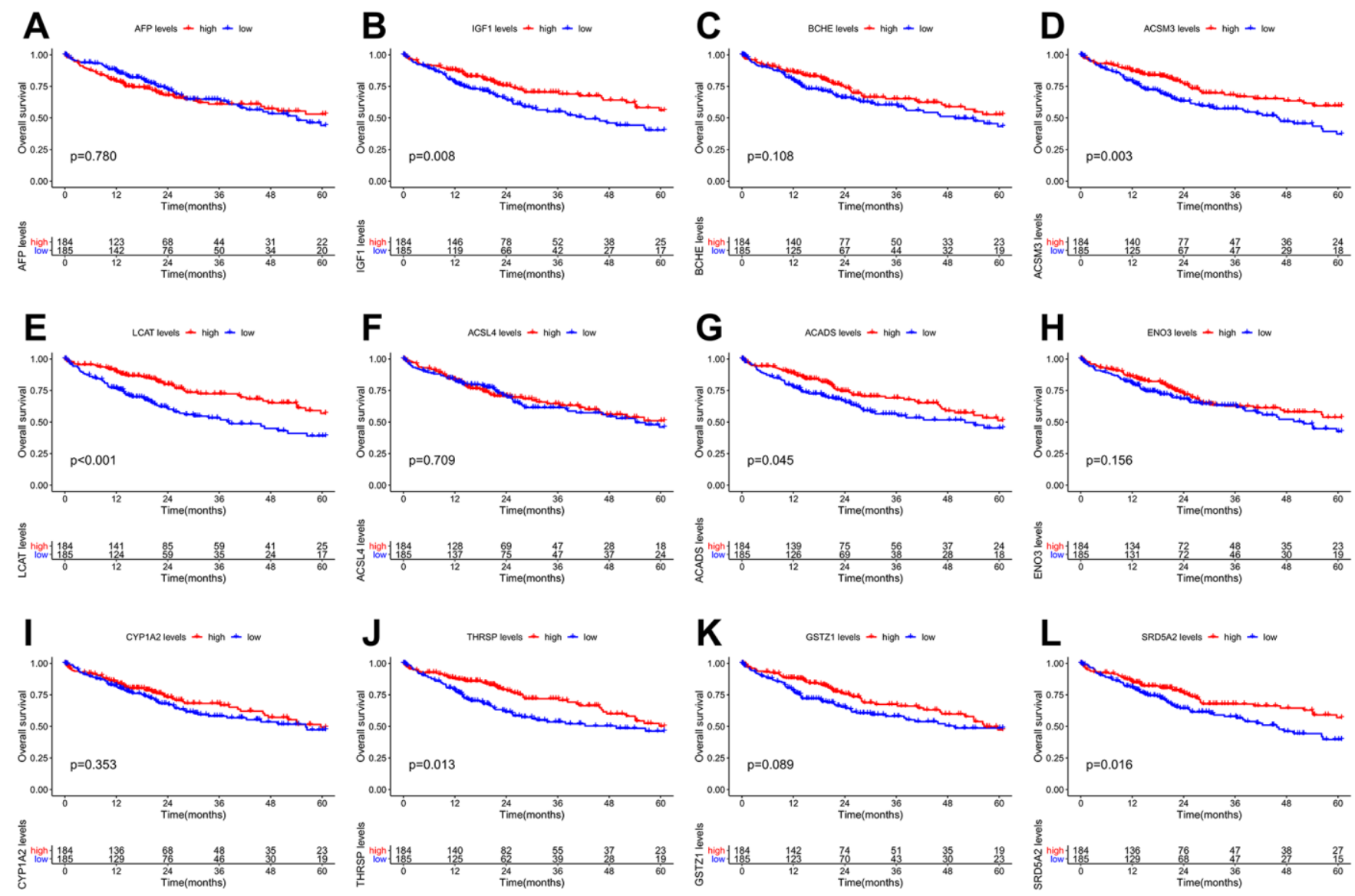

Figure 4. Overall survival (OS) Kaplan-Meier curves of the 12 hub genes in HCC patients. (A) AFP, $p=0.780$. (B) IGF1, $p=0.008$. (C) BCHE, $p=0.108$. (D) ACSM3, $p=0.003$. (E) LCAT, $p<0.001$. (F) ACSL4, $p=0.709$. (G) ACADS, $p=0.045$. (H) ENO3, $p=0.156$. (I) CYP1A2, $p=$ 0.353. (J) THRSP, $p=0.013$. (K) GSTZ1, $p=0.089$. (L) SRD5A2, $p=0.016$. 
macrophage and different types of functional $\mathrm{T}$ cells) in HCC with the TIMER 2.0 database. As listed in Supplementary Table 1, THRSP expression was negatively associated with most of the gene markers.

\section{Silencing of THRSP promoted HCC progression}

To explore the functional roles of THRSP in HCC, three candidate siRNAs of THRSP (THRSP-siRNAs) were transfected into HCCLM3 and Huh-7 cells. qRTPCR was performed to evaluate the inhibition efficiency of the three THRSP-siRNAs. Three THRSP-siRNAs significantly inhibited THRSP

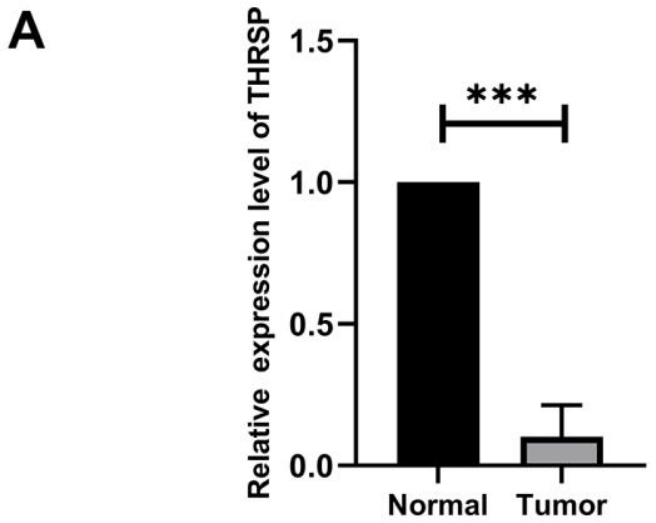

C Case 1
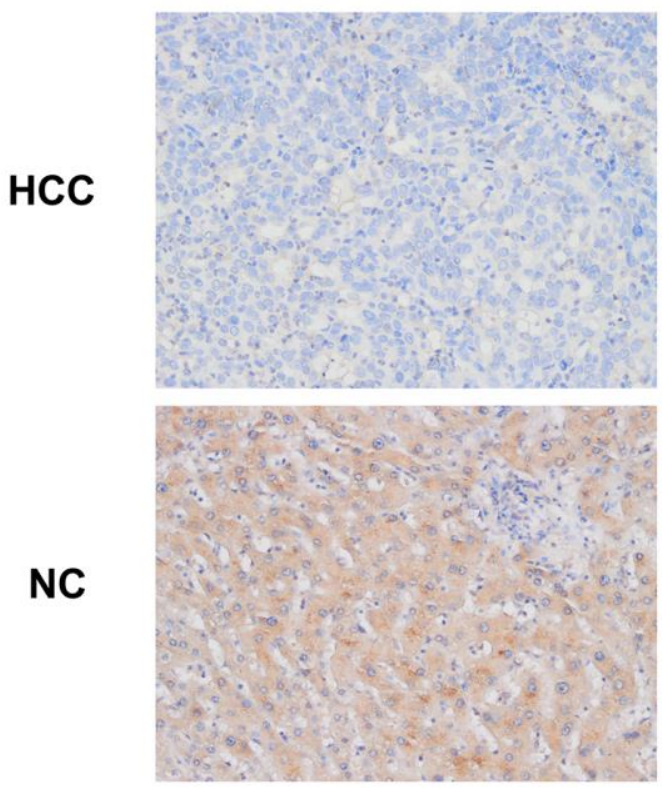

expression compared with the negative control (Figure 6A). The si-THRSP-3 was selected for the following experiments due to its robust silencing efficiency. The CCK-8 assays indicated that silencing of THRSP could promote proliferation of HCCLM3 and Huh7 cells (Figure 6B, 6C). The flow cytometry assays indicated that the si-THRSP group presented a significantly higher percentage of HCCLM3 cells in the $\mathrm{S}$ phase and the $\mathrm{G} 2 / \mathrm{M}$ phase, but a lower percentage of cells in the G0/G1 phase compared with the control group (Figure 6D-6F). Transwell and wound scratch assays indicated that silencing of THRSP also promoted migration and invasion of HCC cells (Figure 7A-7C).

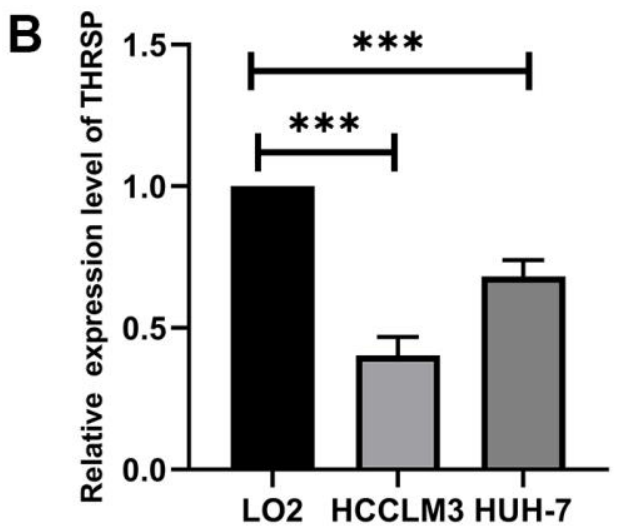

Case 2
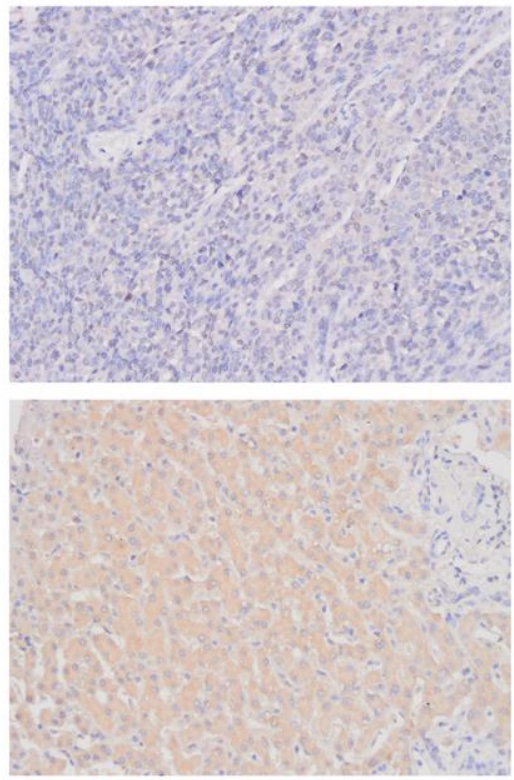

Case 3
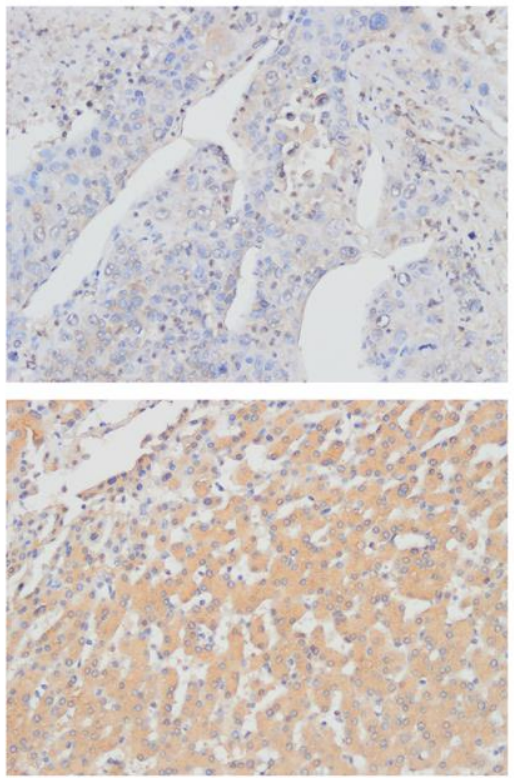

Figure 5. The expression of THRSP at mRNA and protein levels. (A, B) The mRNA expression of THRSP in HCC tissues and cells compared with control examined by RT-qPCR. (C) The protein expression of THRSP in HCC tissues and the adjacent normal tissues examined by immunohistochemical (200x). 
Table 1. Correlations between THRSP expression/methylation and clinical features.

\begin{tabular}{|c|c|c|c|c|c|c|c|}
\hline \multirow{2}{*}{\multicolumn{2}{|c|}{ Clinical features }} & \multicolumn{2}{|c|}{ THRSP expression } & \multirow{4}{*}{$\begin{array}{c}\text { P value } \\
0.0378\end{array}$} & \multicolumn{2}{|c|}{ THRSP methylation } & \multirow{3}{*}{$\begin{array}{c}\text { P value } \\
0.0457\end{array}$} \\
\hline & & \multirow{2}{*}{$\begin{array}{c}\text { Low (\%) } \\
128(68.45)\end{array}$} & \multirow{2}{*}{$\begin{array}{c}\text { High (\%) } \\
107(57.53)\end{array}$} & & \multirow{2}{*}{\begin{tabular}{|c|} 
Low (\%) \\
$108(57.75)$
\end{tabular}} & \multirow{2}{*}{\begin{tabular}{|l|} 
High $(\%)$ \\
$127(68.28)$
\end{tabular}} & \\
\hline & $<=65$ & & & & & & \\
\hline Age & $>65$ & $59(31.55)$ & $79(42.47)$ & & $79(42.25)$ & $59(31.72)$ & \\
\hline \multirow{2}{*}{ Cancer Status } & Tumor-free & $79(55.24)$ & $83(58.04)$ & 0.7204 & $85(59.44)$ & $77(53.85)$ & 0.4036 \\
\hline & With tumor & $64(44.76)$ & $60(41.96)$ & & $58(40.56)$ & $66(46.15)$ & \\
\hline \multirow{4}{*}{ Grade } & G1 & $16(8.65)$ & $39(21.2)$ & $6.00 \mathrm{E}-04$ & $39(21.08)$ & $16(8.7)$ & $3.00 \mathrm{E}-04$ \\
\hline & G2 & $86(46.49)$ & $92(50)$ & & $94(50.81)$ & $84(45.65)$ & \\
\hline & G3 & $74(40)$ & $50(27.17)$ & & $49(26.49)$ & $75(40.76)$ & \\
\hline & G4 & $9(4.86)$ & $3(1.63)$ & & $3(1.62)$ & $9(4.89)$ & \\
\hline \multirow{4}{*}{ Stage } & Stage I & $78(44.57)$ & $95(54.29)$ & 0.1955 & $94(53.71)$ & $79(45.14)$ & 0.2653 \\
\hline & Stage II & $48(27.43)$ & $39(22.29)$ & & $41(23.43)$ & $46(26.29)$ & \\
\hline & Stage III & $45(25.71)$ & $40(22.86)$ & & $39(22.29)$ & $46(26.29)$ & \\
\hline & Stage IV & $4(2.29)$ & $1(0.57)$ & & $1(0.57)$ & $4(2.29)$ & \\
\hline \multirow{2}{*}{$\begin{array}{l}\text { Family history of } \\
\text { cancer }\end{array}$} & NO & $114(70.81 \%)$ & $96(59.63 \%)$ & 0.0467 & $96(59.63)$ & $114(70.81)$ & 0.0467 \\
\hline & YES & $47(29.19 \%)$ & $65(40.37 \%)$ & & $65(40.37)$ & 47(29.19) & \\
\hline \multirow{2}{*}{ Living status } & Alive & $117(62.57)$ & $126(67.74)$ & 0.3472 & $128(68.45)$ & $115(61.83)$ & 0.2175 \\
\hline & Dead & $70(37.43)$ & $60(32.26)$ & & $59(31.55)$ & 71(38.17) & \\
\hline \multirow{4}{*}{ Ishak fibrosis score } & 0 & $28(25.93)$ & $47(43.93)$ & 0.0421 & $48(44.44)$ & $27(25.23)$ & 0.058 \\
\hline & 1,2 & $18(16.67)$ & $13(12.15)$ & & $14(12.96)$ & $17(15.89)$ & \\
\hline & 3,4 & $17(15.74)$ & $11(10.28)$ & & $12(11.11)$ & $16(14.95)$ & \\
\hline & 5,6 & $45(41.67 \%)$ & $36(33.64 \%)$ & & $34(31.48 \%)$ & $47(43.93 \%)$ & \\
\hline \multirow{2}{*}{ Gender } & Female & 71(37.97) & $50(26.74)$ & 0.0271 & $48(25.67)$ & 73(39.04) & 0.008 \\
\hline & Male & $116(62.03)$ & $137(73.26)$ & & $139(74.33)$ & $114(60.96)$ & \\
\hline \multirow{3}{*}{ Race } & Asian & $96(53.04)$ & $64(35.36)$ & $9.00 \mathrm{E}-04$ & $64(35.36)$ & $96(53.04)$ & $9.00 \mathrm{E}-04$ \\
\hline & Black & $4(2.21)$ & $13(7.18)$ & & $13(7.18)$ & $4(2.21)$ & \\
\hline & White & $81(44.75)$ & $104(57.46)$ & & $104(57.46)$ & $81(44.75)$ & \\
\hline expression & Low & - & - & - & $26(13.9 \%)$ & $161(86.1 \%)$ & $<0.001$ \\
\hline expression & High & - & - & & $161(86.1 \%)$ & $26(13.9 \%)$ & \\
\hline methylation & Low & $26(13.9 \%)$ & $161(86.1 \%)$ & $<0.001$ & - & - & - \\
\hline methylation & High & $161(86.1 \%)$ & $26(13.9 \%)$ & & - & - & \\
\hline
\end{tabular}

\section{Silencing of THRSP inhibited apoptosis of HCC cells}

In this study, cells were strained with Annexin V/PI and subjected to flow cytometry to determine the apoptotic cells. The results indicated that silencing of THRSP could inhibit HCC cell apoptosis (Figure 8A, 8B). qRTPCR and Western blotting assays were performed to detect the cell apoptosis-related molecules, including bax, bcl-2 and caspase 3 . The results indicated that silencing of THRSP significantly reduced the expression of bax and caspase 3, while enhanced the expression of bcl-2 (Figure 8C, 8D).

THRSP regulated HCC cell progression by modulating MAPK/NF- $\kappa B$ signaling pathway

To further understand the molecular mechanism by which si-THRSP promoted the migration and invasion of HCC cells, we explored the potential signaling pathways including the NF- $\mathrm{kB}$ and MAPK signaling pathways by Transwell and wound healing assays. As shown in Figure $8 \mathrm{H}-8 \mathrm{~J}$, compared with negative control, the migration and invasion of HCC cells transfected with si-THRSP or si-NC were inhibited after being treated with BAY-11-7082 (NF- $\kappa \mathrm{B}$ inhibitor), AG-126 (ERK1/2 inhibitor), SB203580 (p38 MAPK inhibitor) and SP600125 (JNK inhibitor). And there was no difference between the si-THRSP group and the si-NC group when the cells were treated with BAY-11-7082, AG-126 and SB203580, indicating that the cell migration and invasion caused by the siRNA-induced silencing of THRSP might depend on the NF- $\kappa$ B, ERK1/2 and p38 MAPK signaling pathways. qRT-PCR and Western blotting assays were performed to assess the expression of MAPK/NF- $\kappa$ B pathway-related molecules (p65, p-p65, 
p38, p-p38, erk1/2 and p-erk1/2). The results showed that the silencing of THRSP increased the phosphorylation of ERK1/2, p38 MAPK and p65, and enhanced the expression of p65, p38, and erk1/2 (Figure 8E, 8F). Each of the protein bands were showed in Figure 8G.

\section{DISCUSSION}

HCC is highly malignant with a poor prognosis [13]. Despite advances in radiotherapy, chemotherapy, and surgical resection over the past decades, the 5-year survival rate of HCC remains frustrating [14]. There is

B

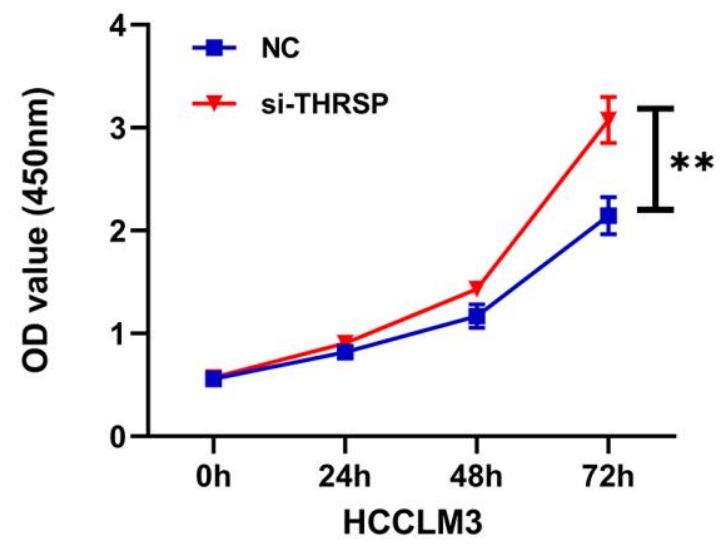

D

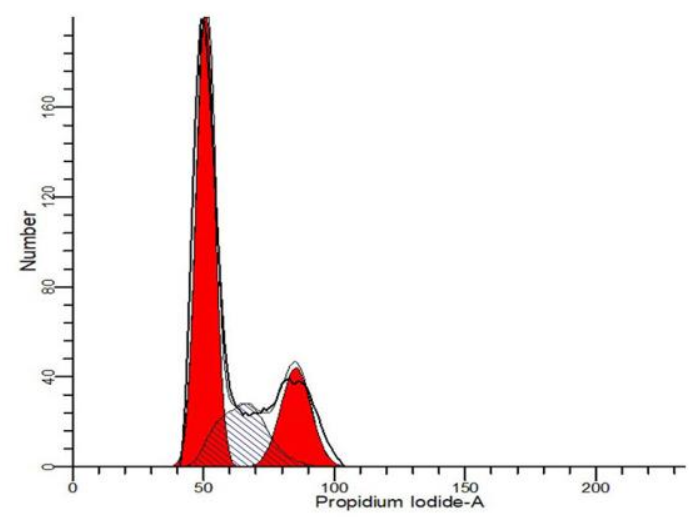

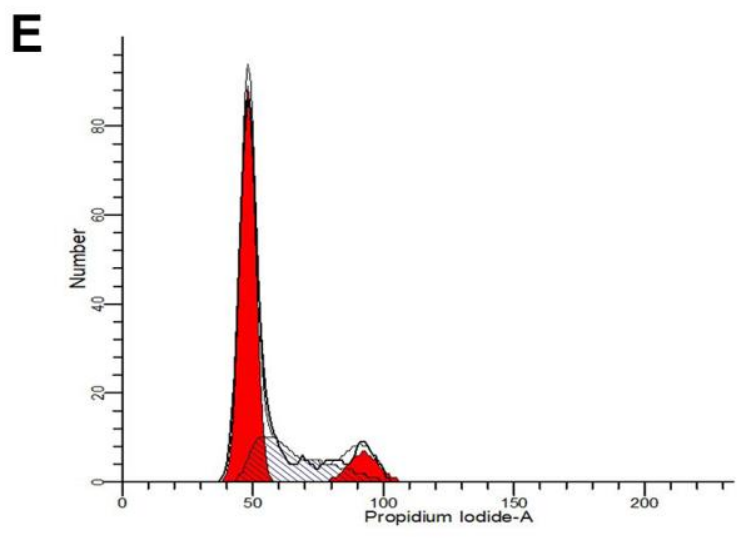

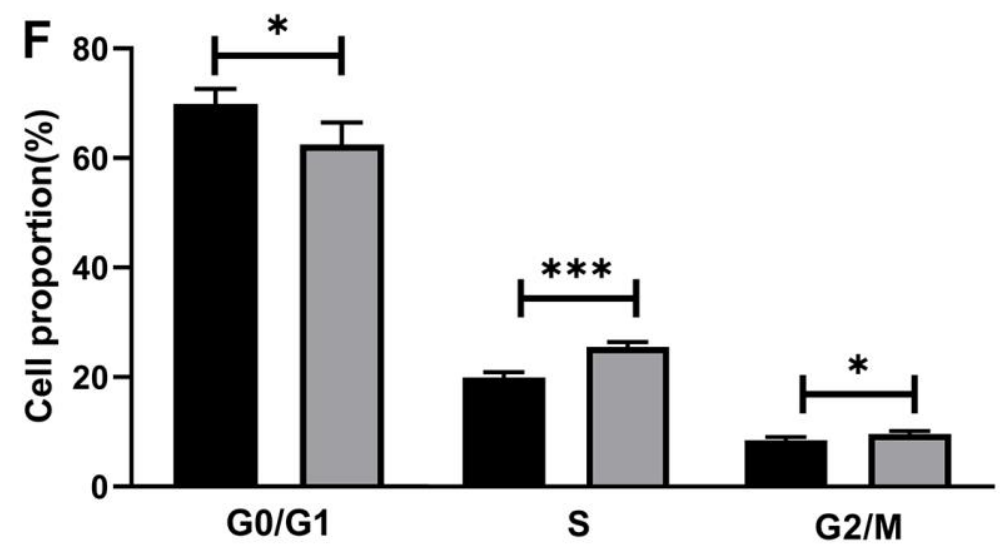

Figure 6. The effect of THRSP expression on proliferation and cell cycle of HCC cells. (A) The efficiency of the THRSP silencing determined by qRT-PCR. (B, C) The proliferation of HCCLM3 and Huh-7 cells examined by CCK-8. (D-F) The cell cycle assay detected by flow cytometry. NC group: black bars; si-THRSP group: grey bars. ${ }^{*} p<0.05,{ }^{* *} p<0.01,{ }^{* * *} p<0.001$. 
an urgent need to identify effective molecular targets to improve diagnostic and therapeutic approaches for HCC. Herein, integrated bioinformatic analysis was performed to identify effective molecular targets on two GEO datasets and the TCGA database. Six genes (namely LCAT, ACSM3, IGF1, SRD5A2, THRSP, and ACADS) were finally defined as survival-related hub genes. The roles of THRSP in HCC progression have rarely been reported. Here, we aimed to investigate biological functions and underlying mechanisms of THRSP in regulating HCC.

In this study, we systematically analyzed the mRNA expression, epigenetic modifications, immune significance, and clinical value of THRSP in HCC by bioinformatics analysis. The results indicated that the expression of THRSP was negatively correlated with its methylation and closely correlated with several clinical characteristics in HCC patients. The HCC patients with higher expression of THRSP have better 5-year survival. In addition, THRSP expression was negatively correlated with most of the immune cells, and it might play an important role in the tumor microenvironment of HCC. The further function experiments implicated that silencing of THRSP could promote cell proliferation, migration, invasion and cell division, and

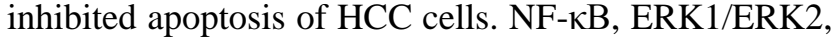
and p38 MAPK signaling pathways were vital for THRSP- mediated HCC progression. Eventually, we concluded that THRSP may be a promising therapeutic target for HCC.

For the other hub genes related to the prognosis of HCC, LCAT (Lecithin-cholesterol acyltransferase) is a plasma enzyme involved in reverse cholesterol transport (RCT) and high-density lipoprotein (HDL) metabolism and has been reported to play an important role in many other cancers, such as breast cancer [15], Hodgkin

\section{A HCCLM3}
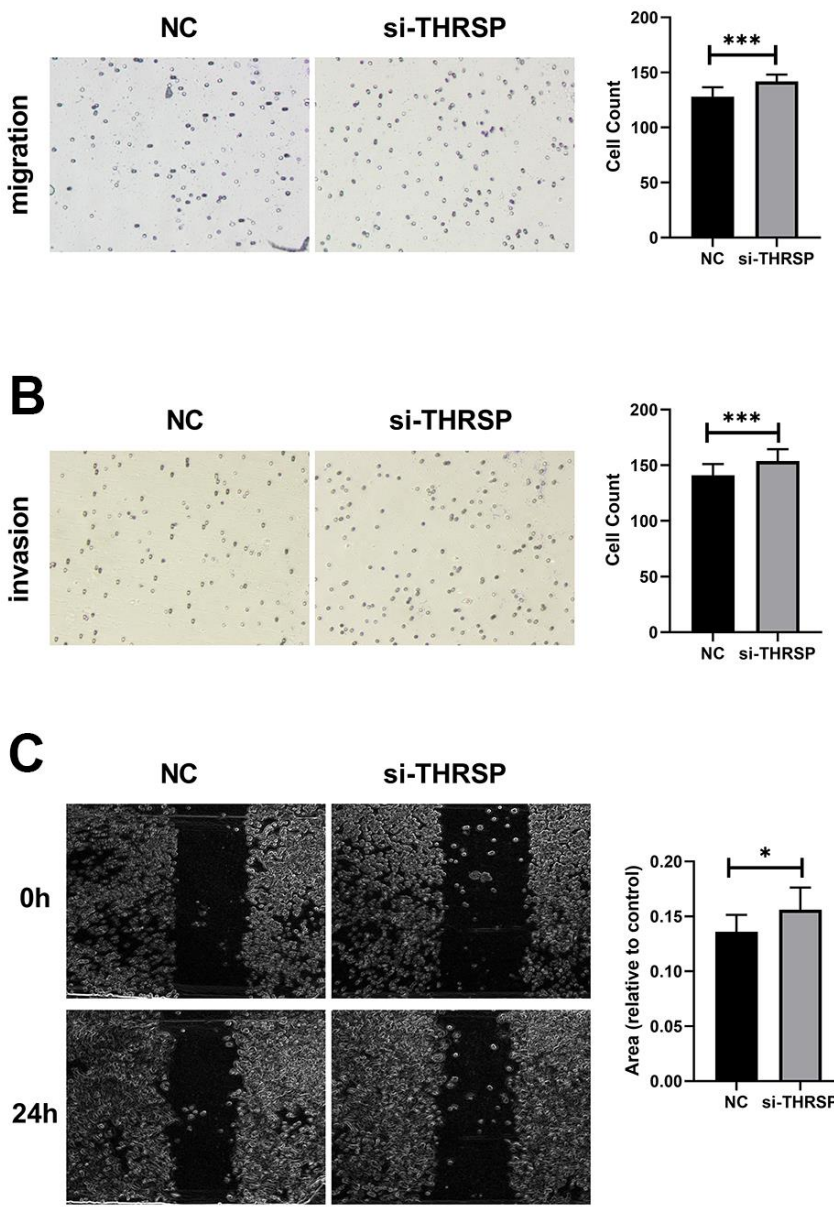

\section{HUH-7}
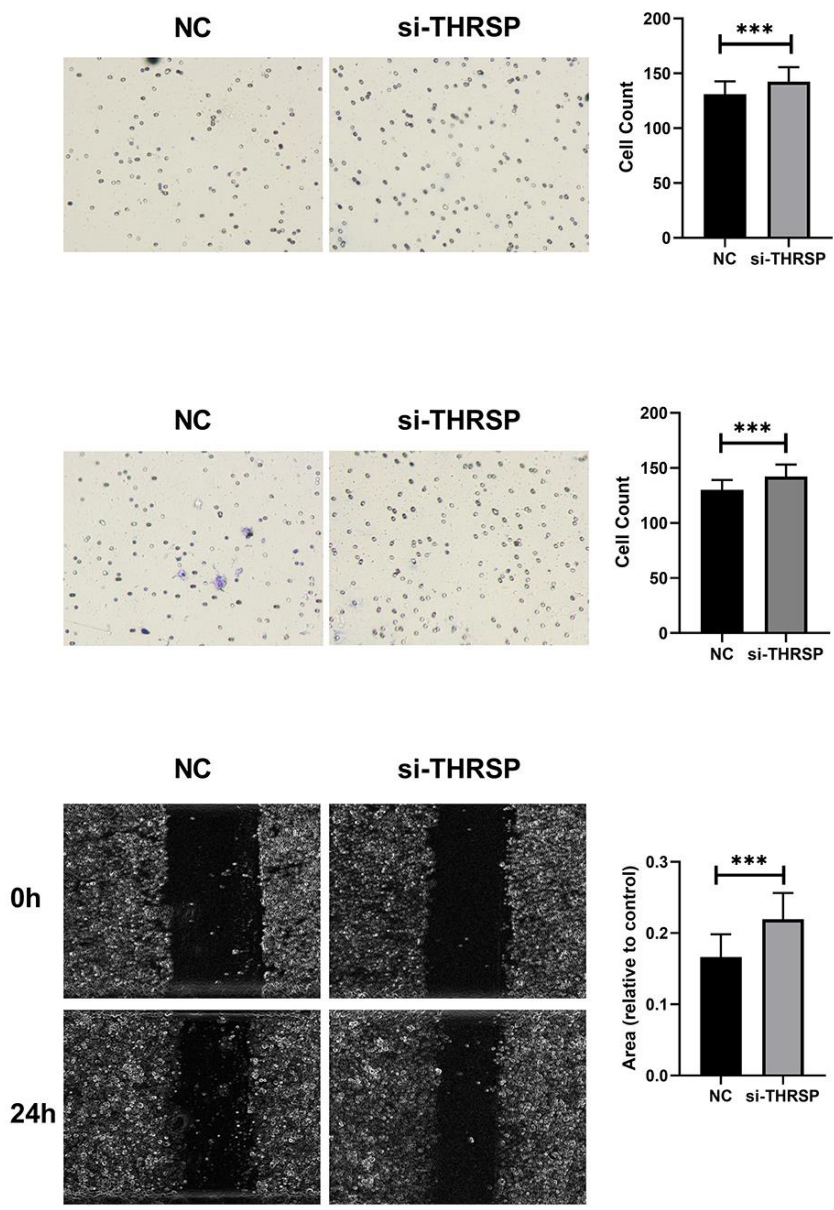

Figure 7. Transwell and wound healing assays. (A, B) The migration and invasion of HCCLM3 and Huh-7 cells detected by Transwell assays (magnification: 200x). (C) The migration ability of HCCLM3 and Huh-7 cells examined by wound healing assays (magnification: 40x). 
lymphoma [16], and ovarian cancer [17]. The previous studies had reported the significantly low expression and high DNA methylation of LCAT in HCC patients [18-20]. Besides, LCAT plays a crucial role in the conversion of liver cirrhosis into HCC [21]. ACSM3, as one member of the acyl-CoA synthetase medium-chain family, was found to be frequently down-regulated in HCC patients exhibiting high AFP levels, high ALT levels, large tumors, and multiple nodules. On the contrary, higher ACSM3 expression was always associated with a better prognosis and may hinder metastasis of HCC by downregulating phosphorylation of WNK1 and AKT [22]. IGF-1 (growth factor-1) has been widely reported that its expression decreased sharply in patients with chronic liver disease such as steatosis, nonalcoholic steatohepatitis, chronic hepatitis $\mathrm{C}$, cirrhosis, and HCC [23-29]. The reason may be that most of the circulating levels of IGF-1 were synthesized by the liver
$[30,31]$. IGF1 synthesis decreases when hepatitis or liver necrosis occurs. In addition, a prospective cohort study demonstrated that IGF-1 can be an independent predictor of survival or recurrence in early HCC [32]. IGF1 was also demonstrated to play an important role in the cellular function aspects of hepatocarcinogenesis and could be a therapeutic target against HCC [33-35]. For instance, Sorafenib could inhibit macrophage-induced growth of hepatoma cells by disrupting IGF1 secretion [34]. SRD5A2, also known as steroid 5-alpha-reductase 2, encodes a microsomal protein. As a membrane-associated enzyme, it catalyzes the transformation of testosterone to dihydrotestosterone (DHT). SRD5A2 is highly expressed in androgen-sensitive tissues such as the prostate and the expression of SRD5A2 is associated with the progression of prostate cancer [36-39]. To date, some reports revealed that SRD5A2 polymorphism may be associated with liver cancer, and it might serve as a robust diagnosis or
A

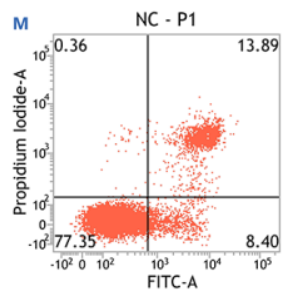

B

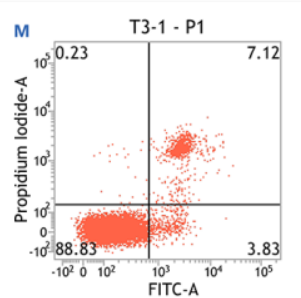

C

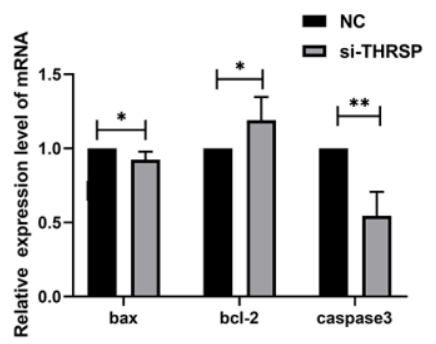

G

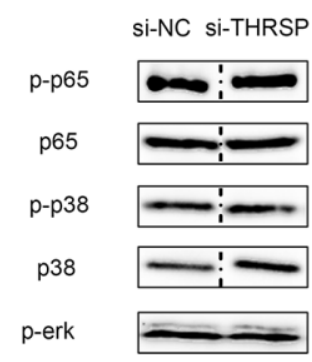

$\mathbf{F}$

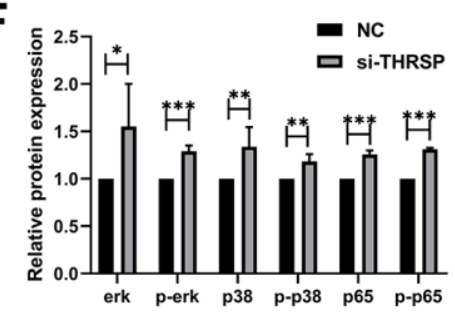

erk

caspase 3

bax

bcl-2

$\beta$-actin

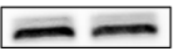

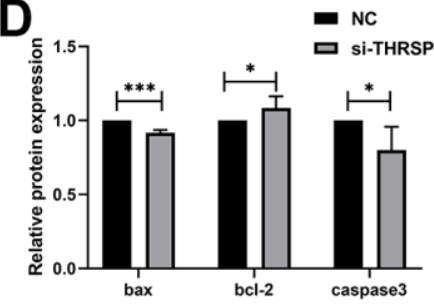
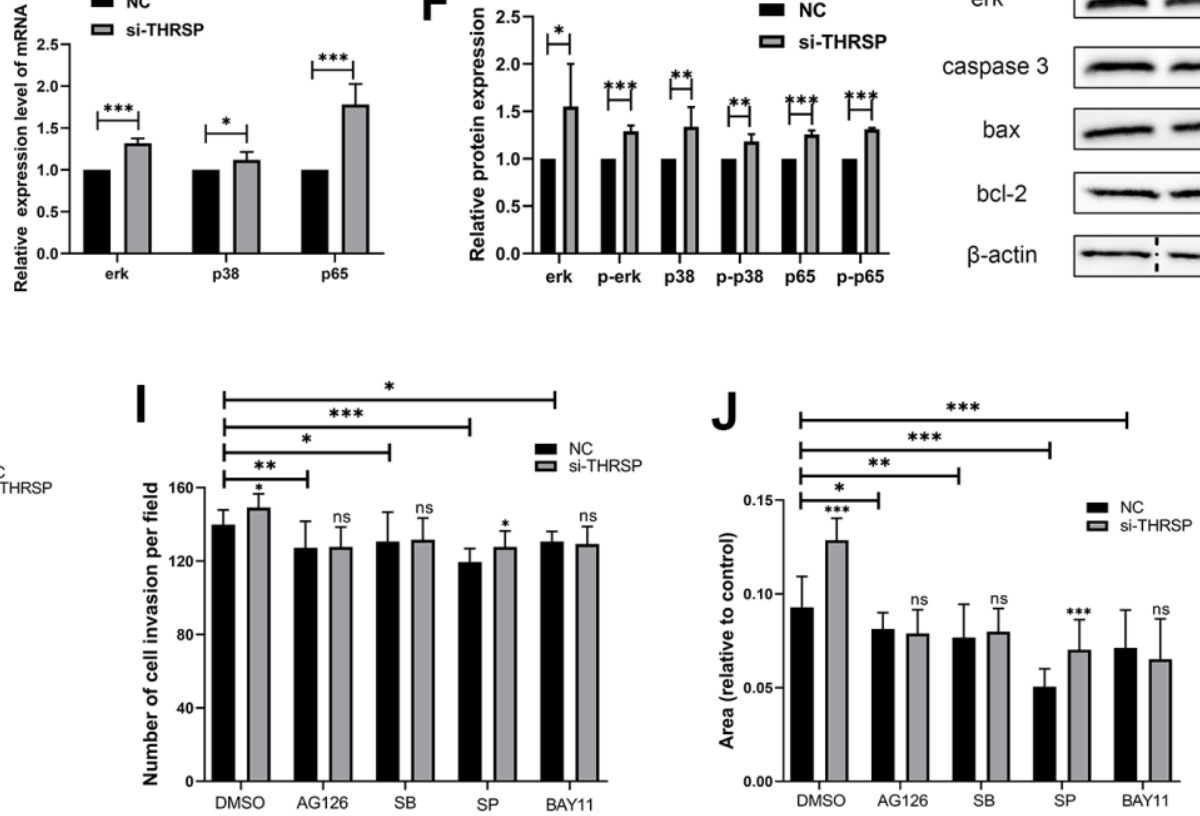

Figure 8. The effect of THRSP expression on cell apoptosis and channel regulation in HCC. (A, B) The apoptosis of HCCLM3 cells detected by flow cytometry. (C-F) The expression of apoptosis-related molecules (bax, bcl-2 and caspase 3) and MAPK/NF-KB pathwayrelated molecules (erk, p-erk, p38, p-p38, p65 and p-p65) examined by qRT-PCR or Western blotting assays. (G) Each of the protein bands. The dividing lines (dashed lines) indicated that the grouping of images were from different parts of the same gel. (H-J) Invasion and migration rates were analyzed when treated with AG-126, SB203580, SP600125 and BAY-11-7082 inhibitors. 
prognosis marker for the diagnosis of HCC [40-42]. ACADS, namely acyl-CoA dehydrogenase short-chain, encodes a tetrameric mitochondrial flavoprotein and catalyzes the initial step of the mitochondrial fatty acid beta-oxidation pathway. It was identified as a potential biomarker in colon adenocarcinoma and bladder cancer $[43,44]$. A previous study demonstrated that ACADS was significantly down-regulated in HCC tissues and was regulated by DNA methylation, which played a key role in promoting the proliferation and metastasis of HCC [45].

In summary, by a series of comprehensive bioinformatics analyses, our study screened six significant survival-related hub genes. Among them, we found a novel biomarker (THRSP) associated with HCC development. The experimental results showed that lower expression of THRSP can promote the progression of HCC cells. Therefore, THRSP has the potential to be a valuable therapeutic target for HCC.

\section{MATERIALS AND METHODS}

\section{Datasets preprocessing}

Two gene expression profiles GSE84005 and GSE121248 were obtained from the GEO database. The GSE84005 dataset, including 38 tumor tissues and paired 38 normal tissues from HCC patients, was based on the GPL5175 platform (Affymetrix Human Exon 1.0 ST Array). The GSE121248 dataset, including 70 HCC tissue samples and 37 adjacent non-tumor tissue samples, was based on the GPL570 platform (Affymetrix Human Genome U133 Plus 2.0 Array). Two datasets were merged by Perl 5.3 (available online: http://www.perl.org/) to increase the sample size. The merged dataset was batch-normalized by "limma" and "sva" packages in R 3.6.3 (https://www.rproject.org/) to remove batch effects.

Besides, the RNA-sequencing (RNA-seq) data of 373 HCC and 49 normal samples and the corresponding clinical information was downloaded from the TCGA database. As recommended by the package "edgeR" in $\mathrm{R}$, genes with low read counts (count per million (cpm) $\leq 1$ ) were omitted. Gene expression was calculated and normalized to RPKM (reads per kilobase per million) values using function "rpkm" in the "edgeR" package. Moreover, DNA promoter methylation data (Methylation 450k, including 430 samples) was downloaded from the TCGA database via the UCSC Xena browser (https://xenabrowser.net/).

\section{WGCNA analysis}

The "WGCNA" package in R was applied to construct co-expression networks and to explore the key modules of highly relevant genes by cluster analysis for relating modules to sample traits. In this study, the gene expression profiles of TCGA-LIHC and the merged dataset of GSE84005 and GSE121248 were respectively used to construct WGCNA. Briefly: an adjacency matrix was created by Pearson's correlations between each of the gene pairs. Next, the adjacency matrix was utilized to erect a scale-free coexpression network based on the soft threshold power $\beta$ which was selected using the pickSoftThreshold function [46]. Subsequently, the adjacency matrix was converted into a topological overlap matrix (TOM) as well as the corresponding dissimilarity (1-TOM). Then, module identification was conducted using the dynamic tree Cut approach by average linkage hierarchical clustering based on the TOM-based dissimilarity measure with the parameters of minModuleSize of 50, deepSplit value of 2, and mergeCutHeight of 0.25 for the genes dendrogram. Afterward, the correlation between module eigengenes (MEs) and the clinical trait information was calculated by the module-trait relationship analysis of WGCNA to identify the clinically significant modules in a co-expression network. Finally, modules with a high correlation coefficient were selected for further analysis.

\section{Identification of differentially co-expressed genes}

The "limma" package in $\mathrm{R}$ was used to filter the DEGs between the HCC and normal samples in the TCGA-LIHC and the merged dataset of GSE84005 and GSE121248. The adjusted P-value (adj. P) $<0.05$ and $\mid \log 2$ foldchange (FC) $\mid>1$ was set as the criteria of DEGs. Then, the overlapping genes between DEG lists and co-expression genes from significant modules were screened out using the "VennDiagram" package in $\mathrm{R}$.

\section{Identification of hub genes}

The PPI network was constructed in the STRING (http://string-db.org) and visualized by the Cytoscape software (Cytoscape_v3.8.0, https://cytoscape.org/) [47]. The maximal clique centrality (MCC) analysis was performed to extract the candidate hub genes with the top20 MCC values in the PPI network using the cytoHubba plug-in [48]. Meanwhile, the Molecular Complex Detection (MCODE) [49] plug-in of Cytoscape was implemented to find significant PPI modules with degree cut-off $\geq 2$, node score cut-off $\geq 0.2$, K-core $\geq 2$, and max. depth $=100$. Finally, the overlapping genes obtained from the MCC analysis and MCODE analysis were regarded as hub genes. 
The gene expression and prognostic analysis of the hub genes

The differential expression analysis of the hub genes between HCC and normal tissues was performed based on the GEPIA2 database. The 5-year overall survival (OS) analysis of these hub genes was performed using the "survival" and "survminer" packages in $\mathrm{R}$ [50].

\section{The correlation between gene expression and clinical features}

According to the median value of gene expression or methylation, the HCC patients were divided into the low- or high- group. The chi-square test was utilized to investigate the correlation of gene expression as well as methylation with clinical characteristics. The correlation between DNA methylation and gene expression in HCC samples from the TCGA database was examined using the Spearman correlation coefficient and visualized by "ggplot2" and "ggpubr" packages in $\mathrm{R}$.

\section{Immune infiltrate analysis}

The online tool TIMER 2.0 (https://cistrome. shinyapps.io/timer/) was used for immune infiltrate analysis [51]. The abundance of six types of immune cells (including CD8+ T cells, CD4+ T cells, B cells, neutrophils, macrophages, and dendritic cells) were computed by TIMER algorithm. In addition, we exploited the correlation between gene expression and the gene markers of different kinds of immune cells. The immune gene markers of interest used in this study were referred to the previous studies [52-56].

\section{Cell culture}

The human normal liver cell line (LO2) and the human hepatoma cell lines (HCCLM3 and HUH-7) were purchased from Procell Life Science and Technology Co., Ltd. (Wuhan, China). The cells were cultured in DMEM (Servicebio Technology Co., Ltd, Wuhan, China) supplemented with $10 \%$ Fetal Bovine Serum (FBS, G-CLONE, Beijing, China) and maintained in a incubator with $5 \% \mathrm{CO} 2$-humidified atmosphere at $37^{\circ} \mathrm{C}$.

\section{Total RNA extraction and qPCR}

The quantitative real-time polymerase chain reaction (qRT-PCR) was employed to detect the expressions of THRSP. GAPDH was served as a reference gene. Total RNA was extracted from tissues and cells by the TRIzol reagent (G-CLONE, Beijing, China). The expression of
THRSP was determined by the SweScript RT I First Strand cDNA Synthesis Kit with gDNA Remover and the SYBR Green qPCR Master Mix (High ROX) (Servicebio Technology Co., Wuhan, China) according to the manufacturer's protocol. The qRT-PCR was performed on the StepOne Plus Real-Time PCR Systems. The primers used in this study were as follows: THRSP forward: 5'-CAGGTGCTAACCAAG CGTTAC-3', THRSP reverse: 5'-CAGAAGGCTGGG GATCATCA-3'; GAPDH forward: 5'-GGACCTGACC TGCCGTCTAG-3', GAPDH reverse: 5'-GTAGCCCA GGATGCCCTTGA-3'.

\section{IHC analysis}

10 pairs of HCC tissues and paracancerous tissues were fixed in formalin, dehydrated, and embedded in paraffin. The paraffin sections were deparaffinized for antigen retrieval and treated with 3\% hydrogen peroxide for blocking peroxidase activity, with $3 \%$ bovine serum albumin (BSA) for serum sealing. Afterward, the paraffin sections were incubated with primary THRSP antibody (Guangzhou Alexan Biotech Co., Ltd., China) overnight at $4^{\circ} \mathrm{C}$, and then with HRP-conjugated secondary antibody for $50 \mathrm{~min}$ at room temperature. 3,3'-Diaminobenzidine (DAB) liquid substrate was used for staining and the hematoxylin solution was used for nucleus counterstaining. Finally, after dehydration and mounting, a microscope was used to acquire images of the staining of tissues.

\section{Transfection of small interfering RNA}

Three short interfering RNAs (siRNAs) of THRSP (T1: 5'-ACACCTACTTCACCATGCT-3'; T2: 5'-CCAGGA AATGACGGGACAA-3'; T3: 5'-CATGCACCTCACCG AGAAA-3') and negative control siRNA (si-NC) were purchased from RiboBio Co., Ltd. (Guangzhou, China). HCCLM3 and Huh-7 cells $\left(2 \times 10^{5}\right.$ per well $)$ were inoculated on 24-well plates for $24 \mathrm{~h}$ and then transfected with $25 \mathrm{pmol}$ of the RNA duplex according to the manufacturer's protocol of Lipofectamine 2000 (Invitrogen, Grand Island, NY, USA). After 24h, the transfected cells were harvested for the following experiments.

\section{CCK-8 assay}

The transfected HCCLM3 and Huh-7 cells were seeded into 96 -well plates $\left(3 \times 10^{3}\right.$ cells/well $)$ and incubated for $24 \mathrm{~h}, 48 \mathrm{~h}$ and $72 \mathrm{~h}$. At each time point, $10 \mu \mathrm{l}$ of CCK-8 reagent (Guangzhou Alexan Biotech Co., Ltd., China) was dripped into each well and the cells were cultured for an extra 4h. A micro-plate reader was used to detect the absorbance at $450 \mathrm{~nm}$ to evaluate cell proliferation. 


\section{Transwell and scratch wound healing assays}

Transwell assays were used to determine the migration and invasion ability of the HCC cells. The transfected HCCLM3 cells and Huh-7 cells in $200 \mu$ serum-free DMEM $(5 \times 104$ cells/well $)$ were plated into the upper chamber and $600 \mu 1$ of complete medium was added in the lower chamber. For cell invasion assay, the Transwell chamber was coated with Matrigel (Beijing Solarbio Science and Technology Co., Ltd., China). After incubating at $37^{\circ} \mathrm{C}$ for $24 \mathrm{~h}$, the remaining cells in the upper chamber were removed by a cotton swab. The cells that have invaded to the lower surface of the filter were fixed with $4 \%(\mathrm{v} / \mathrm{v})$ neutral formaldehyde solution (Servicebio, Wuhan, China) for 30min and stained with $0.1 \%$ Crystal violet for $30 \mathrm{~min}$. Finally, the cells in ten random microscope fields of each filter were counted.

The transfected HCCLM 3 and Huh- 7 cells $\left(5 \times 10^{5}\right.$ cells per well) were seeded into 24-well plates. When the cell confluence reaches $90 \%$, a scratch wound was created using a sterilized pipette tip $(200 \mu \mathrm{l})$ on confluent cells. The images of wounds were acquired with a phasecontrast light (40x) at $0 \mathrm{~h}$ and $24 \mathrm{~h}$. The heal area of each scratch wound was determined by ImageJ.

To further understand the molecular mechanism, the potential signaling pathways including the NF- $\mathrm{KB}$ and MAPK signaling pathways were detected by Transwell and wound healing assays. Briefly: post of transfection for $48 \mathrm{~h}$, the cells were harvested and pre-treated with

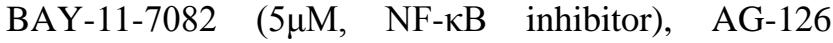

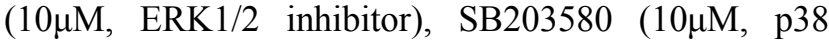

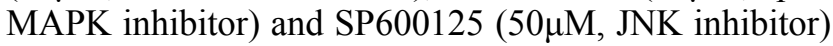
for $2 \mathrm{~h}$ in serum-free DMEM medium. Then, the cells were cultured in the DMEM medium containing inhibitors for 24 hours after being seeded into Transwell chambers or culture wells. The cells treated with dimethyl sulfoxide (DMSO) were used as the negative control.

\section{Flow cytometry}

For the cell cycle assays, after $48 \mathrm{~h}$ of transfection, the HCCLM3 cells were trypsinized, and washed with cold phosphate-buffered saline (PBS) and then fixed in $70 \%$ cold ethanol at $4^{\circ} \mathrm{C}$ for $24 \mathrm{~h}$. After centrifuging and washing, the cells were stained with $500 \mu \mathrm{l}$ PI buffer $(50 \mu \mathrm{g} / \mathrm{mL}$, containing RNase, Beijing Leagene Biotechnology Co., Ltd., China) at $37^{\circ} \mathrm{C}$ in the dark for $30 \mathrm{~min}$. The cell cycle distribution was determined by the Flow cytometer after PI staining. The apoptosis analysis was performed following the instruction of Annexin-V Apoptosis Detection kit (Jiangsu KeyGEN BioTECH Co., Ltd. China). Briefly, $72 \mathrm{~h}$ posttransfection, the trypsinized cells were washed with cold PBS twice and re-suspended in binding buffer, and then stained with Annexin V-FITC and PI at room temperature for 5-15 min in the dark. The apoptotic cells were analyzed by flow cytometry within an hour.

\section{Western blotting}

The total protein was extracted with the nucleoprotein and cytoplasmic protein extraction kit (Jiangsu Keygen Biotech Co., Ltd., China) and quantified by the BCA protein assay kit (Beijing Bomaide Gene Technology Co., Ltd., China). After that, the protein solution was subjected to electrophoresis, detached via SDS-PAGE (12\% gels), and transferred to PVDF membranes. The PVDF membranes were blocked with $5 \%$ skim milk powder in TBST (Tris buffered saline with $0.5 \%$ Tween 20) for $2 \mathrm{~h}$, and then incubated with primary antibodies overnight at $4^{\circ} \mathrm{C}$. After washing with TBST for 5 times, the PVDF membranes were incubated with secondary antibody at room temperature for an hour. The protein bands were exposed by enhanced chemiluminescent (ECL) substrate kit (Labgic Technology Co., Ltd. Hefei, China) and analyzed by ImageJ software. The Anti-Bcl2 antibody, Anti-Caspase-3 antibody, Anti-Bax antibody, Anti-NF- $\kappa \mathrm{B}$ p65 antibody and Anti-NF- $\kappa \mathrm{B}$ p65 (phospho S536) antibody were purchased from Abcam. The p38 MAPK, Phospho-p38 MAPK (Thr180/Tyr182), P44/42 MAPK (Erk1/2), and Phospho-p44/42 MAPK (Erk1/2) (Thr202/Tyr204) were purchased from Cell Signaling Technology. $\beta$-actin was severed as the internal control and anti- $\beta$-actin was purchased from Labgic Technology Co., Ltd.

\section{Ethics approval}

The manuscript has been approved by the ethics committee of the affiliated hospital of Southwest Medical University (Ethical ID: KY2021142).

\section{Abbreviations}

HCC: hepatocellular carcinoma; GEO: Gene Expression Omnibus; TCGA: The Cancer Genome Atlas; DEGs: differentially expressed genes; WGCNA: Weighted Gene Co-expression Network Analysis; PPI: proteinprotein interaction; THRSP: thyroid hormoneresponsive; LIHC: liver hepatocellular carcinoma; STRING: search tool for the retrieval of interacting genes; MCC: maximal clique centrality; MCODE: molecular complex detection; OS: overall survival; GEPIA: Gene Expression Profiling Analysis; FDR: false discovery rate; qRT-PCR: quantitative real-time polymerase chain reaction; TIMER: Tumor Immune Estimation Resource; siRNA: small interfering RNA; DMSO: Dimethyl sulfoxide; NC group: normal control group; PBS: phosphate-buffered saline; SDS-PAGE: 
sodium dodecyl sulfate polyacrylamide gel electrophoresis; PVDF: polyvinylidene fluoride; TBST: tris-buffer saline tween; ECL: enhanced chemiluminescence.

\section{AUTHOR CONTRIBUTIONS}

Yuxi Ding, Changfeng Sun, and Cunliang Deng conceptualized the project and developed the methodology. Xiaoling Liu, Changfeng Sun, Yuxi Ding, Yue Yuan and Decheng Li performed the experiments. Yuxi Ding and Xiaoling Liu analyzed the data, prepared figures and/or tables. Yuxi Ding wrote the manuscript. Changfeng Sun, Xiaoling Liu, Yunjian Sheng, and Suvash Chandra Ojha revised the manuscript. All authors have read and approved the final version of the manuscript for publication.

\section{CONFLICTS OF INTEREST}

The authors declare that they have no conflicts of interest.

\section{FUNDING}

This study was financed by grants from the scientific research project of the Sichuan Provincial Health and Family Planning Commission (18PJ340); the Luzhou Municipal People's Government-Southwest Medical University Science and Technology Strategic Cooperation Applied Basic Research Project (2018LZXNYD-ZK29); Scientific Research Project for Young Researchers of Southwest Medical University (2017-ZRQN-103); the Affiliated Hospital of Southwest Medical University Research Grant (16237 and 16251). We would like to thank Tiejun Zhou and Jun Liu of the Pathology Department of Southwest Medical University for the guidance on pathology.

\section{REFERENCES}

1. Sung $H$, Ferlay J, Siegel RL, Laversanne $M$, Soerjomataram I, Jemal A, Bray F. Global Cancer Statistics 2020: GLOBOCAN Estimates of Incidence and Mortality Worldwide for 36 Cancers in 185 Countries. CA Cancer J Clin. 2021; 71:209-49. https://doi.org/10.3322/caac.21660 PMID:33538338

2. Dutta R, Mahato RI. Recent advances in hepatocellular carcinoma therapy. Pharmacol Ther. 2017; 173:106-17. https://doi.org/10.1016/i.pharmthera.2017.02.010 PMID:28174094

3. Cancer Genome Atlas Research Network, Weinstein JN, Collisson EA, Mills GB, Shaw KR, Ozenberger BA, Ellrott K, Shmulevich I, Sander C, Stuart JM. The Cancer
Genome Atlas Pan-Cancer analysis project. Nat Genet. 2013; 45:1113-20. https://doi.org/10.1038/ng.2764 PMID:24071849

4. Edgar R, Domrachev M, Lash AE. Gene Expression Omnibus: $\mathrm{NCBI}$ gene expression and hybridization array data repository. Nucleic Acids Res. 2002; 30:207-10. https://doi.org/10.1093/nar/30.1.207 PMID:11752295

5. Langfelder P, Horvath S. WGCNA: an R package for weighted correlation network analysis. BMC Bioinformatics. 2008; 9:559.

https://doi.org/10.1186/1471-2105-9-559

PMID: 19114008

6. Szklarczyk D, Morris JH, Cook H, Kuhn M, Wyder S, Simonovic M, Santos A, Doncheva NT, Roth A, Bork P, Jensen $L$, von Mering C. The STRING database in 2017: quality-controlled protein-protein association networks, made broadly accessible. Nucleic Acids Res. 2017; 45:D362-8. https://doi.org/10.1093/nar/gkw937 PMID:27924014

7. Seelig S, Jump DB, Towle HC, Liaw C, Mariash CN, Schwartz HL, Oppenheimer JH. Paradoxical effects of cycloheximide on the ultra-rapid induction of two hepatic mRNA sequences by triiodothyronine (T3). Endocrinology. 1982; 110:671-3.

https://doi.org/10.1210/endo-110-2-671 PMID: $\underline{6276146}$

8. Cunningham BA, Moncur JT, Huntington JT, Kinlaw WB. "Spot 14" protein: a metabolic integrator in normal and neoplastic cells. Thyroid. 1998; 8:815-25.

https://doi.org/10.1089/thy.1998.8.815 PMID: 9777755

9. Chella Krishnan K, Kurt Z, Barrere-Cain R, Sabir S, Das A, Floyd R, Vergnes L, Zhao Y, Che N, Charugundla S, Qi H, Zhou Z, Meng Y, et al. Integration of Multi-omics Data from Mouse Diversity Panel Highlights Mitochondrial Dysfunction in Non-alcoholic Fatty Liver Disease. Cell Syst. 2018; 6:103-115.e7.

https://doi.org/10.1016/i.cels.2017.12.006 PMID:29361464

10. Jump DB, Narayan P, Towle H, Oppenheimer JH. Rapid effects of triiodothyronine on hepatic gene expression. Hybridization analysis of tissue-specific triiodothyronine regulation of mRNAS14. J Biol Chem. 1984; 259:2789-97.

https://doi.org/10.1016/S0021-9258(17)43215-7 PMID: 6199351

11. Kinlaw WB, Quinn JL, Wells WA, Roser-Jones C, Moncur JT. Spot 14: A marker of aggressive breast cancer and a potential therapeutic target. Endocrinology. 2006; 147:4048-55.

https://doi.org/10.1210/en.2006-0463 PMID:16809441 
12. Wellberg EA, Rudolph MC, Lewis AS, Padilla-Just N, Jedlicka P, Anderson SM. Modulation of tumor fatty acids, through overexpression or loss of thyroid hormone responsive protein spot 14 is associated with altered growth and metastasis. Breast Cancer Res. 2014; 16:481.

https://doi.org/10.1186/s13058-014-0481-z

PMID:25472762

13. Torre LA, Bray F, Siegel RL, Ferlay J, Lortet-Tieulent J, Jemal A. Global cancer statistics, 2012. CA Cancer J Clin. 2015; 65:87-108.

https://doi.org/10.3322/caac.21262 PMID:25651787

14. Allemani C, Weir HK, Carreira H, Harewood R, Spika D, Wang XS, Bannon F, Ahn JV, Johnson CJ, Bonaventure A, Marcos-Gragera R, Stiller C, Azevedo e Silva G, et al, and CONCORD Working Group. Global surveillance of cancer survival 1995-2009: analysis of individual data for 25,676,887 patients from 279 population-based registries in 67 countries (CONCORD-2). Lancet. 2015; 385:977-1010.

https://doi.org/10.1016/S0140-6736(14)62038-9 PMID:25467588

15. Subbaiah PV, Liu M, Witt TR. Impaired cholesterol esterification in the plasma in patients with breast cancer. Lipids. 1997; 32:157-62.

https://doi.org/10.1007/s11745-997-0020-5 PMID: $\underline{9075205}$

16. Cooke AL, Morris J, Melchior JT, Street SE, Jerome WG, Huang R, Herr AB, Smith LE, Segrest JP, Remaley AT, Shah AS, Thompson TB, Davidson WS. A thumbwheel mechanism for APOA1 activation of LCAT activity in HDL. J Lipid Res. 2018; 59:1244-55.

https://doi.org/10.1194/jlr.M085332 PMID:29773713

17. Russell MR, Graham C, D’Amato A, Gentry-Maharaj A, Ryan A, Kalsi JK, Ainley C, Whetton AD, Menon U, Jacobs I, Graham RL. A combined biomarker panel shows improved sensitivity for the early detection of ovarian cancer allowing the identification of the most aggressive type II tumours. Br J Cancer. 2017; 117:666-74.

https://doi.org/10.1038/bjc.2017.199 PMID:28664912

18. Long J, Chen $P$, Lin J, Bai $Y$, Yang $X$, Bian J, Lin Y, Wang $D$, Yang $X$, Zheng $Y$, Sang $X$, Zhao H. DNA methylationdriven genes for constructing diagnostic, prognostic, and recurrence models for hepatocellular carcinoma. Theranostics. 2019; 9:7251-67.

https://doi.org/10.7150/thno.31155 PMID:31695766

19. Zheng Y, Liu Y, Zhao S, Zheng Z, Shen C, An L, Yuan Y. Large-scale analysis reveals a novel risk score to predict overall survival in hepatocellular carcinoma. Cancer Manag Res. 2018; 10:6079-96.

https://doi.org/10.2147/CMAR.S181396

PMID: $\underline{30538557}$
20. Ouyang G, Yi B, Pan G, Chen X. A robust twelve-gene signature for prognosis prediction of hepatocellular carcinoma. Cancer Cell Int. 2020; 20:207.

https://doi.org/10.1186/s12935-020-01294-9

PMID:32514252

21. Jiang $\mathrm{CH}$, Yuan $\mathrm{X}$, Li JF, Xie YF, Zhang AZ, Wang XL, Yang $L$, Liu CX, Liang WH, Pang $L$, Zou $H$, Cui XB, Shen $X H$, et al. Bioinformatics-based screening of key genes for transformation of liver cirrhosis to hepatocellular carcinoma. J Transl Med. 2020; 18:40.

https://doi.org/10.1186/s12967-020-02229-8 PMID: $\underline{32000807}$

22. Ruan HY, Yang C, Tao XM, He J, Wang T, Wang H, Wang C, Jin GZ, Jin HJ, Qin WX. Downregulation of ACSM3 promotes metastasis and predicts poor prognosis in hepatocellular carcinoma. Am J Cancer Res. 2017; 7:543-53.

PMID:28401010

23. Buzzelli G, Dattolo P, Pinzani M, Brocchi A, Romano S, Gentilini P. Circulating growth hormone and insulin-like growth factor-I in nonalcoholic liver cirrhosis with or without superimposed hepatocarcinoma: evidence of an altered circadian rhythm. Am J Gastroenterol. 1993; 88:1744-8.

PMID: 8213718

24. Kaseb AO, Morris JS, Hassan MM, Siddiqui AM, Lin E, Xiao L, Abdalla EK, Vauthey JN, Aloia TA, Krishnan S, Abbruzzese JL. Clinical and prognostic implications of plasma insulin-like growth factor-1 and vascular endothelial growth factor in patients with hepatocellular carcinoma. J Clin Oncol. 2011; 29:3892-9.

https://doi.org/10.1200/JCO.2011.36.0636 PMID:21911725

25. Luo SM, Tan WM, Deng WX, Zhuang SM, Luo JW. Expression of albumin, IGF-1, IGFBP-3 in tumor tissues and adjacent non-tumor tissues of hepatocellular carcinoma patients with cirrhosis. World J Gastroenterol. 2005; 11:4272-6.

https://doi.org/10.3748/wjg.v11.i27.4272 PMID:16015705

26. García-Galiano D, Sánchez-Garrido MA, Espejo I, Montero JL, Costán G, Marchal T, Membrives A, Gallardo-Valverde JM, Muñoz-Castañeda JR, Arévalo E, De la Mata M, Muntané J. IL-6 and IGF-1 are independent prognostic factors of liver steatosis and non-alcoholic steatohepatitis in morbidly obese patients. Obes Surg. 2007; 17:493-503.

https://doi.org/10.1007/s11695-007-9087-1 PMID:17608262

27. Stuver SO, Kuper H, Tzonou A, Lagiou P, Spanos E, Hsieh CC, Mantzoros C, Trichopoulos D. Insulin-like growth factor 1 in hepatocellular carcinoma and 
metastatic liver cancer in men. Int J Cancer. 2000; 87:118-21.

https://doi.org/10.1002/1097-0215(20000701)87:1 <118::AID-IJC17>3.0.CO;2-W PMID:10861461

28. Mazziotti G, Sorvillo F, Morisco F, Carbone A, Rotondi M, Stornaiuolo G, Precone DF, Cioffi M, Gaeta GB, Caporaso N, Carella C. Serum insulin-like growth factor I evaluation as a useful tool for predicting the risk of developing hepatocellular carcinoma in patients with hepatitis $C$ virus-related cirrhosis: a prospective study. Cancer. 2002; 95:2539-45. https://doi.org/10.1002/cncr.11002 PMID: 12467068

29. Su TS, Liu WY, Han SH, Jansen M, Yang-Fen TL, P'eng FK, Chou CK. Transcripts of the insulin-like growth factors I and II in human hepatoma. Cancer Res. 1989; 49:1773-7.

PMID:2466561

30. Yakar S, Liu JL, Stannard B, Butler A, Accili D, Sauer B, LeRoith D. Normal growth and development in the absence of hepatic insulin-like growth factor I. Proc Natl Acad Sci USA. 1999; 96:7324-9.

https://doi.org/10.1073/pnas.96.13.7324 PMID:10377413

31. Daughaday $\mathbf{W H}$. The possible autocrine/paracrine and endocrine roles of insulin-like growth factors of human tumors. Endocrinology. 1990; 127:1-4.

https://doi.org/10.1210/endo-127-1-1

PMID:2163304

32. Cho EJ, Lee JH, Yoo JJ, Choi WM, Lee MJ, Cho Y, Lee DH, Lee YB, Kwon JH, Yu SJ, Lee JM, Suh KS, Kim K, et al. Serum insulin-like growth factor-I level is an independent predictor of recurrence and survival in early hepatocellular carcinoma: a prospective cohort study. Clin Cancer Res. 2013; 19:4218-27.

https://doi.org/10.1158/1078-0432.CCR-12-3443

PMID:23757355

33. Xia Q, Han $T$, Yang $P$, Wang $R$, Li H, Zhang J, Zhou X. MicroRNA-28-5p Regulates Liver Cancer Stem Cell Expansion via IGF-1 Pathway. Stem Cells Int. 2019; 2019:8734362.

https://doi.org/10.1155/2019/8734362

PMID:31885628

34. Sprinzl MF, Puschnik A, Schlitter AM, Schad A, Ackermann K, Esposito I, Lang H, Galle PR, Weinmann A, Heikenwälder $M$, Protzer $U$. Sorafenib inhibits macrophage-induced growth of hepatoma cells by interference with insulin-like growth factor-1 secretion. J Hepatol. 2015; 62:863-70.

https://doi.org/10.1016/j.jhep.2014.11.011

PMID:25463538

35. Chen YM, Qi S, Perrino S, Hashimoto M, Brodt $P$. Targeting the IGF-Axis for Cancer Therapy:
Development and Validation of an IGF-Trap as a Potential Drug. Cells. 2020; 9:E1098.

https://doi.org/10.3390/cells9051098 PMID:32365498

36. Makridakis NM, Ross RK, Pike MC, Crocitto LE, Kolonel LN, Pearce CL, Henderson BE, Reichardt JK. Association of mis-sense substitution in SRD5A2 gene with prostate cancer in African-American and Hispanic men in Los Angeles, USA. Lancet. 1999; 354:975-8. https://doi.org/10.1016/S0140-6736(98)11282-5 PMID:10501358

37. Luo J, Dunn TA, Ewing CM, Walsh PC, Isaacs WB. Decreased gene expression of steroid 5 alphareductase 2 in human prostate cancer: implications for finasteride therapy of prostate carcinoma. Prostate. 2003; 57:134-9.

https://doi.org/10.1002/pros.10284

PMID:12949937

38. Iehlé C, Radvanyi F, Gil Diez de Medina S, Ouafik LH, Gérard H, Chopin D, Raynaud JP, Martin PM. Differences in steroid 5alpha-reductase iso-enzymes expression between normal and pathological human prostate tissue. J Steroid Biochem Mol Biol. 1999; 68:189-95.

https://doi.org/10.1016/S0960-0760(99)00030-8 PMID: 10416833

39. Nam RK, Toi A, Vesprini D, Ho M, Chu W, Harvie S, Sweet J, Trachtenberg J, Jewett MA, Narod SA. V89L polymorphism of type-2, 5-alpha reductase enzyme gene predicts prostate cancer presence and progression. Urology. 2001; 57:199-204.

https://doi.org/10.1016/S0090-4295(00)00928-6 PMID:11164181

40. Tsunedomi R, Ogawa $\mathrm{Y}$, lizuka N, Sakamoto K, Tamesa T, Moribe T, Oka M. The assessment of methylated BASP1 and SRD5A2 levels in the detection of early hepatocellular carcinoma. Int J Oncol. 2010; 36:205-12.

PMID:19956849

41. Rossi L, Leveri M, Gritti C, De Silvestri A, Zavaglia C, Sonzogni L, Silvestri L, Civardi E, Mondelli MU, Silini EM. Genetic polymorphisms of steroid hormone metabolizing enzymes and risk of liver cancer in hepatitis C-infected patients. J Hepatol. 2003; 39:564-70.

https://doi.org/10.1016/S0168-8278(03)00355-6 PMID: 12971967

42. Moribe $T$, lizuka N, Miura T, Stark M, Tamatsukuri S, Ishitsuka H, Hamamoto Y, Sakamoto K, Tamesa T, Oka $M$. Identification of novel aberrant methylation of BASP1 and SRD5A2 for early diagnosis of hepatocellular carcinoma by genome-wide search. Int J Oncol. 2008; 33:949-58.

PMID:18949357 
43. Liu CP, Zhang JH, Zheng SC, Liu J, Guo JC. A novel clinical multidimensional transcriptome signature predicts prognosis in bladder cancer. Oncol Rep. 2018; 40:2826-35.

https://doi.org/10.3892/or.2018.6677 PMID:30226624

44. Pang B, Xu X, Lu Y, Jin H, Yang R, Jiang C, Shao D, Liu Y, Shi J. Prediction of new targets and mechanisms for quercetin in the treatment of pancreatic cancer, colon cancer, and rectal cancer. Food Funct. 2019; 10:5339-49.

https://doi.org/10.1039/C9FO01168D PMID:31393490

45. Chen D, Feng X, Lv Z, Xu X, Lu Y, Wu W, Wu H, Liu H, Cao L, Ye S, Chen J, Wu J. ACADS acts as a potential methylation biomarker associated with the proliferation and metastasis of hepatocellular carcinomas. Aging (Albany NY). 2019; 11:8825-44.

https://doi.org/10.18632/aging.102292

PMID:31652420

46. Horvath S, Dong J. Geometric interpretation of gene coexpression network analysis. PLOS Comput Biol. 2008; 4:e1000117.

https://doi.org/10.1371/journal.pcbi.1000117 PMID:18704157

47. Su G, Morris JH, Demchak B, Bader GD. Biological network exploration with Cytoscape 3. Curr Protoc Bioinformatics. 2014; 47:8.13.1-24.

https://doi.org/10.1002/0471250953.bi0813s47 PMID:25199793

48. Chin $\mathrm{CH}$, Chen $\mathrm{SH}, \mathrm{Wu} \mathrm{HH}$, Ho CW, Ko MT, Lin CY. cytoHubba: identifying hub objects and sub-networks from complex interactome. BMC Syst Biol. 2014 (Suppl 4); 8:S11.

https://doi.org/10.1186/1752-0509-8-S4-S11 PMID:25521941

49. Bandettini WP, Kellman P, Mancini C, Booker OJ, Vasu S, Leung SW, Wilson JR, Shanbhag SM, Chen MY, Arai AE. MultiContrast Delayed Enhancement (MCODE) improves detection of subendocardial myocardial infarction by late gadolinium enhancement cardiovascular magnetic resonance: a clinical validation study. J Cardiovasc Magn Reson. 2012; 14:83.
https://doi.org/10.1186/1532-429X-14-83 PMID:23199362

50. Goel MK, Khanna P, Kishore J. Understanding survival analysis: Kaplan-Meier estimate. Int J Ayurveda Res. 2010; 1:274-8.

https://doi.org/10.4103/0974-7788.76794 PMID:21455458

51. Li T, Fu J, Zeng Z, Cohen D, Li J, Chen Q, Li B, Liu XS. TIMER2.0 for analysis of tumor-infiltrating immune cells. Nucleic Acids Res. 2020; 48:W509-14. https://doi.org/10.1093/nar/gkaa407 PMID:32442275

52. Gu Y, Li X, Bi Y, Zheng Y, Wang J, Li X, Huang Z, Chen L, Huang $Y$, Huang Y. CCL14 is a prognostic biomarker and correlates with immune infiltrates in hepatocellular carcinoma. Aging (Albany NY). 2020; 12:784-807.

https://doi.org/10.18632/aging.102656 PMID:31927532

53. Danaher $P$, Warren $S$, Dennis L, D'Amico L, White A, Disis ML, Geller MA, Odunsi K, Beechem J, Fling SP. Gene expression markers of Tumor Infiltrating Leukocytes. J Immunother Cancer. 2017; 5:18. https://doi.org/10.1186/s40425-017-0215-8 PMID:28239471

54. Liu B, Fan Y, Song Z, Han B, Meng Y, Cao P, Tan K. Identification of DRP1 as a prognostic factor correlated with immune infiltration in breast cancer. Int Immunopharmacol. 2020; 89:107078.

https://doi.org/10.1016/j.intimp.2020.107078

PMID:33049497

55. Zhong L, Xie L, Yang Z, Li L, Song S, Cao D, Liu Y. Prognostic value of S1PR1 and its correlation with immune infiltrates in breast and lung cancers. BMC Cancer. 2020; 20:766.

https://doi.org/10.1186/s12885-020-07278-2 PMID:32799825

56. Lin X, Wang Z, Yang G, Wen G, Zhang H. YTHDF2 correlates with tumor immune infiltrates in lowergrade glioma. Aging (Albany NY). 2020; 12:18476-500. https://doi.org/10.18632/aging.103812 PMID:32986017 


\section{SUPPLEMENTARY MATERIALS}

\section{Supplementary Figures}

A
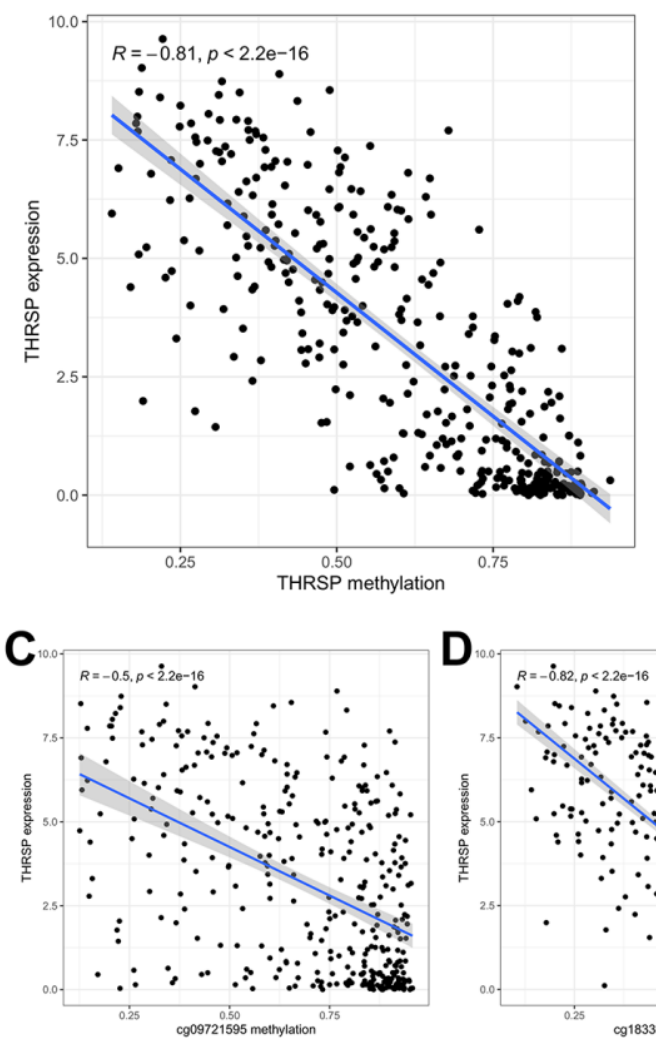

B

B $^{1.00} 1$
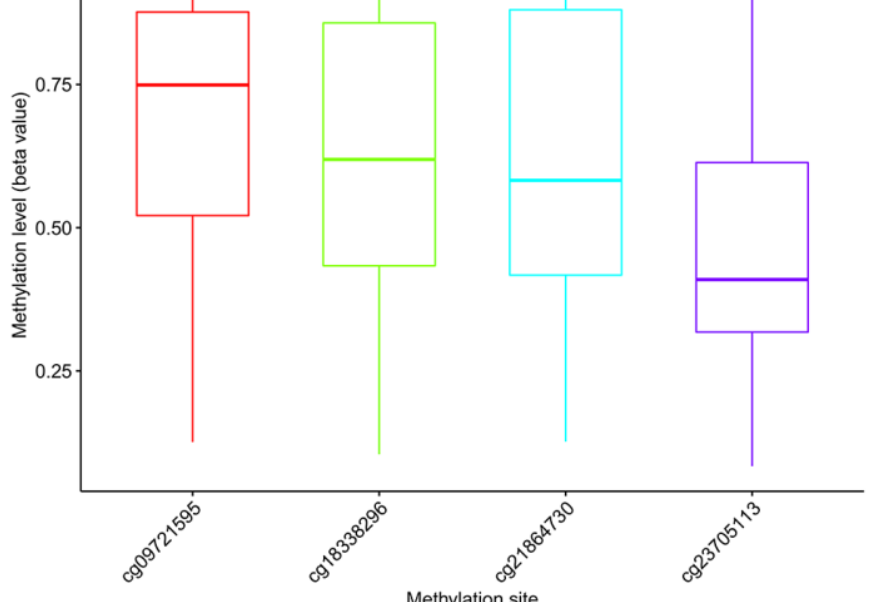

Methylation site
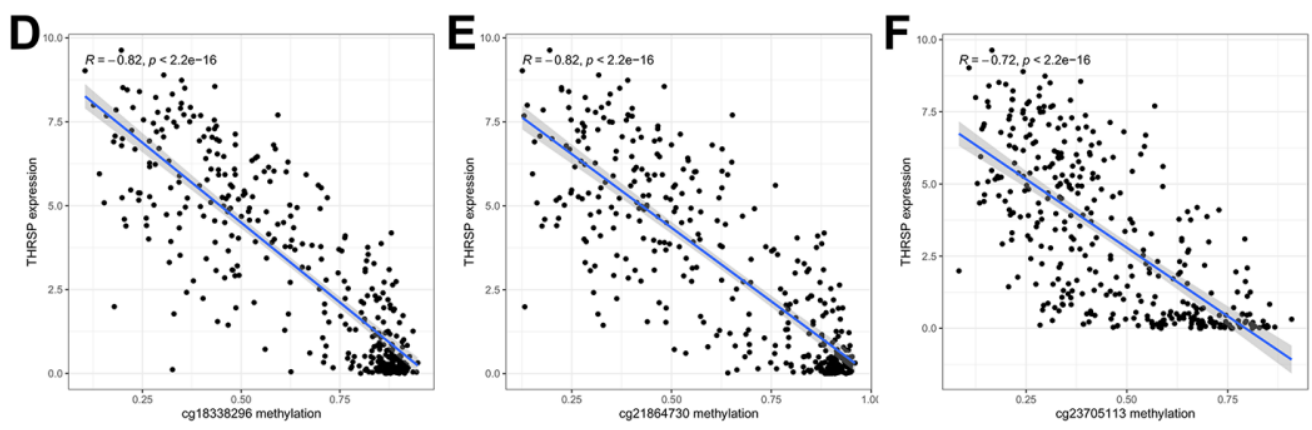

Supplementary Figure 1. Relationship between THRSP mRNA expression and DNA methylation. (A) THRSP expression was negatively correlated with DNA methylation $(R=-0.81, p<2.2 e-16)$. (B) The distribution of four THRSP DNA promoter CpG sites. (C-F) THRSP expression was negatively correlated with the methylation levels of the four $\mathrm{CpG}$ sites. From the left to right were $\operatorname{cg} 09721595(R=-0.5, p<$ 2.2e-16), $\operatorname{cg} 18338296(R=-0.82, p<2.2 e-16), \operatorname{cg} 21864730(R=-0.82, p<2.2 e-16)$ and $\operatorname{cg} 23705113(R=-0.72, p<2.2 e-16)$. 
A Age 自 $\mathrm{A}(<40)$ 审 $\mathrm{B}(40-64)$ 自 $\mathrm{C}(>=65)$

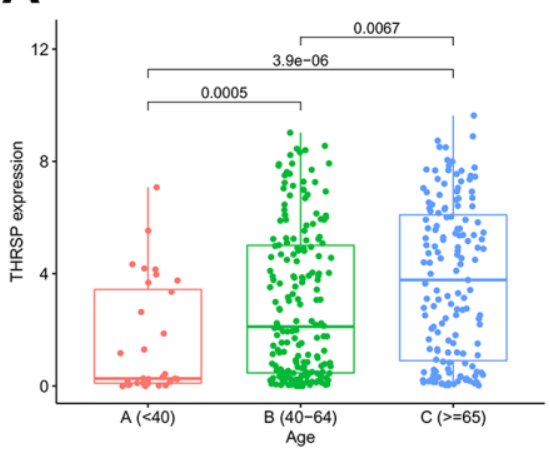

D Grade 审 G1 审 G2 审 G3 审 G4

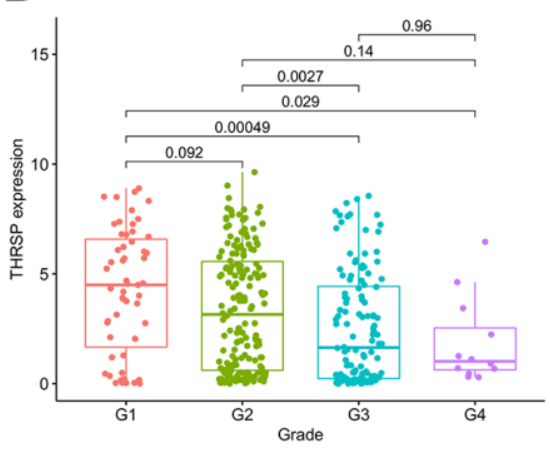

B Family history of cancer 审 No 审 YES

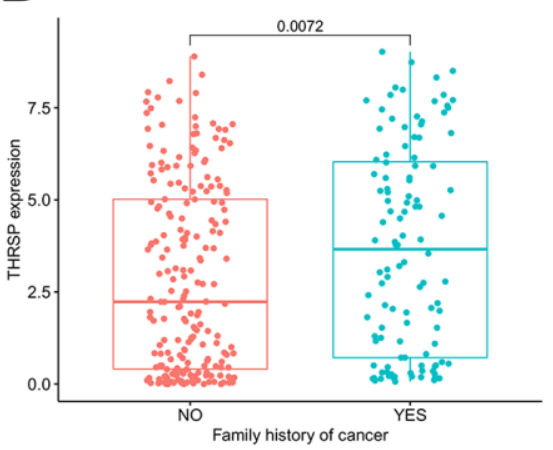

E

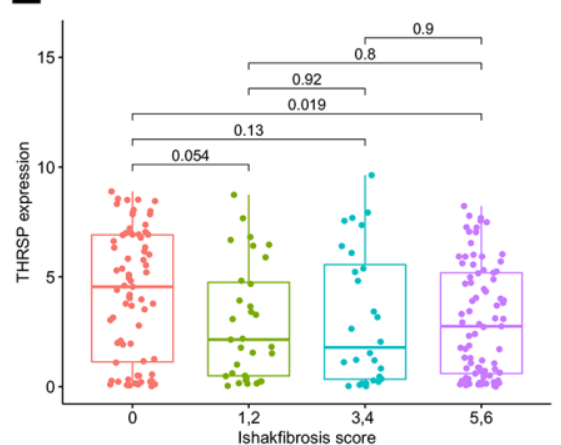

C Gender 审 Female 审 Male

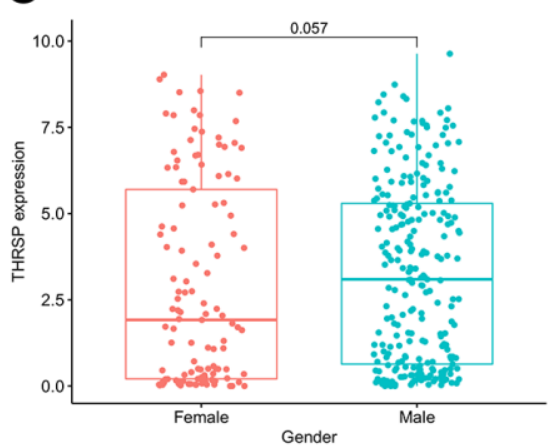

F

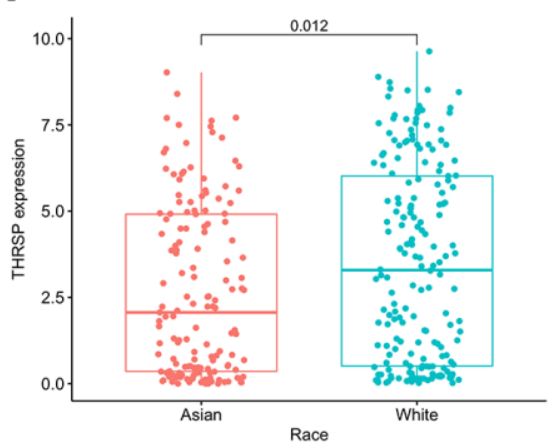

Supplementary Figure 2. The correlation between THRSP expression and the clinical features. THRSP mRNA expression was stratified by (A) age, (B) family history of cancer, (C) gender, (D) grade, (E) Ishak fibrosis score, and (F) race. 

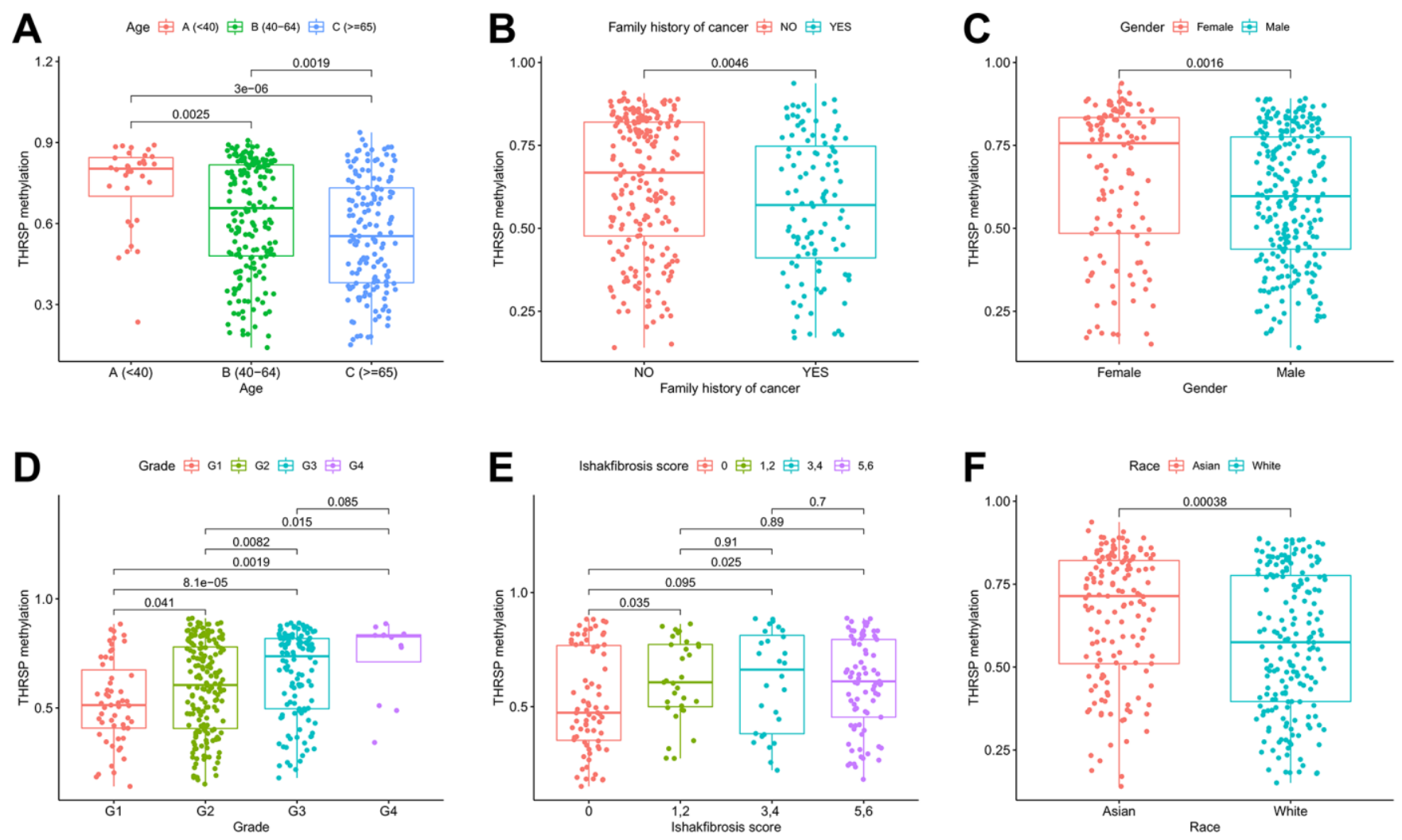

Supplementary Figure 3. The correlation between THRSP methylation and the clinical features. THRSP methylation was stratified by (A) age, (B) family history of cancer, (C) gender, (D) grade, (E) Ishak fibrosis score, and (F) race. 

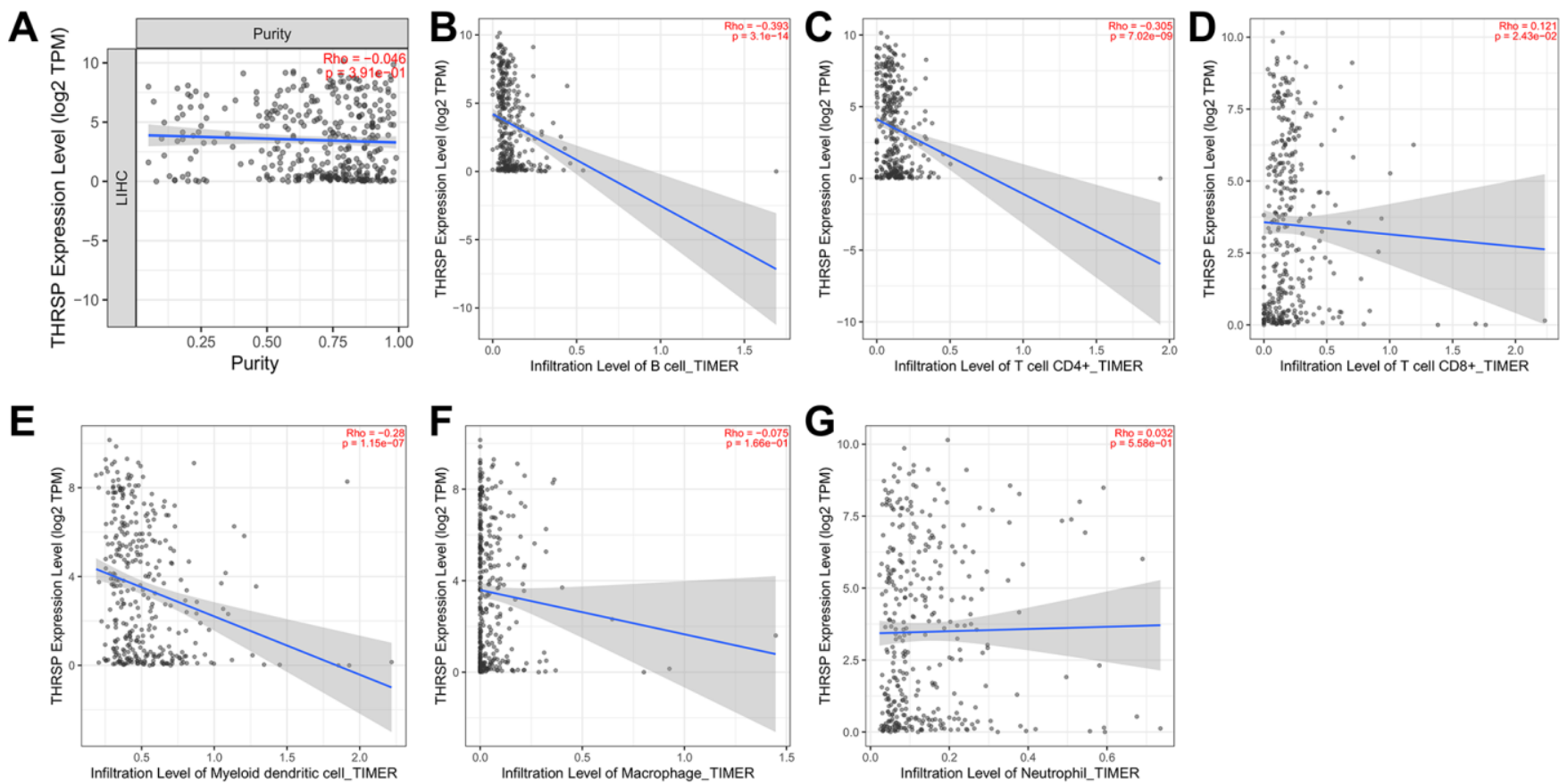

Supplementary Figure 4. The correlation between THRSP expression and immune infiltration levels in HCC. (A) No association between THRSP expression and tumor purity $(R=-0.046, p=0.391)$. (B-G) THRSP expression was significantly negatively correlated with infiltrating levels of B cells, CD4+ T cells, and dendritic cells, positively correlated with CD8+ T cells, but not correlated with macrophages or neutrophils. 


\section{Supplementary Table}

Supplementary Table 1. Correlations between THRSP and related genes and markers of immune cells.

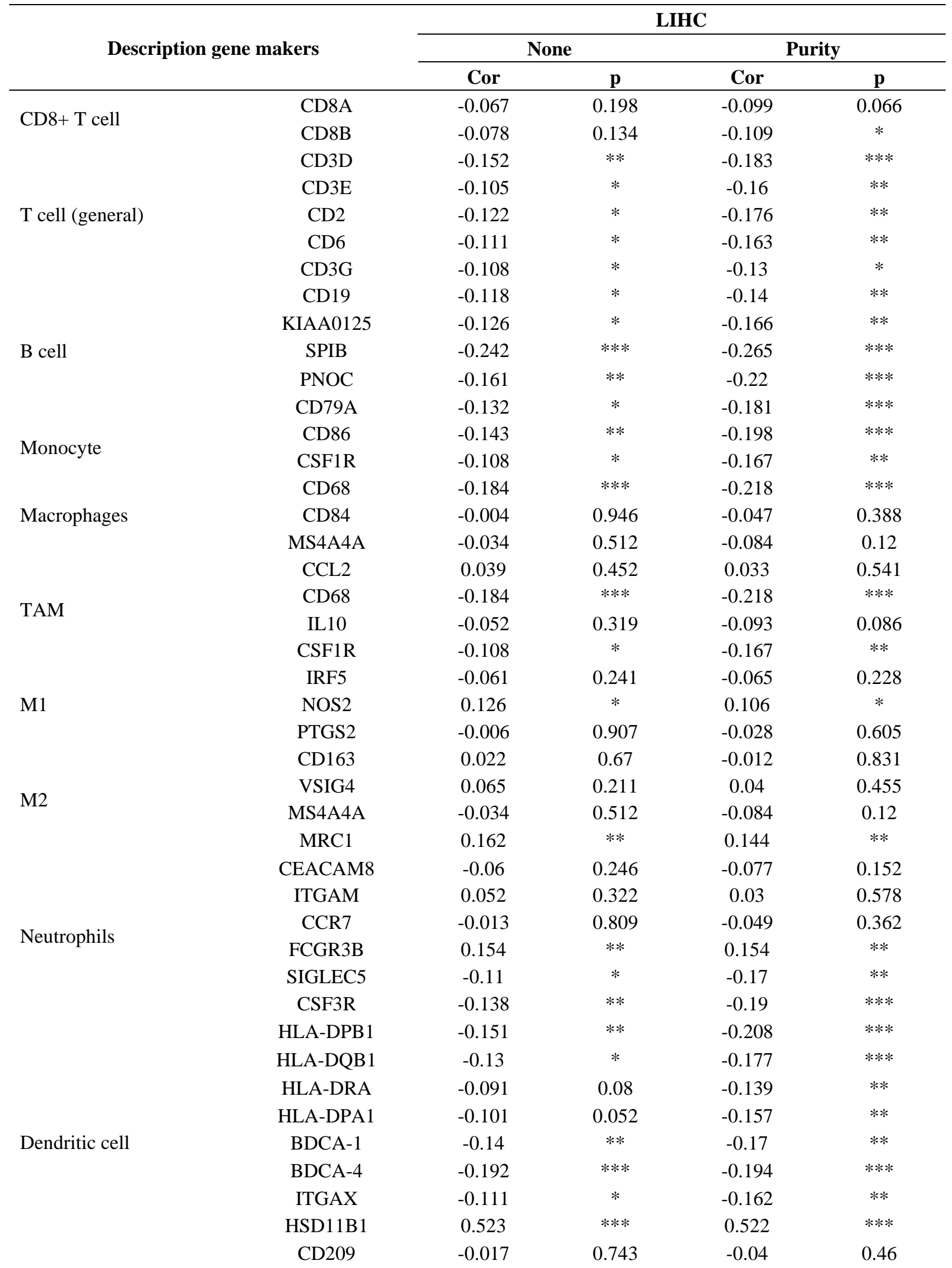




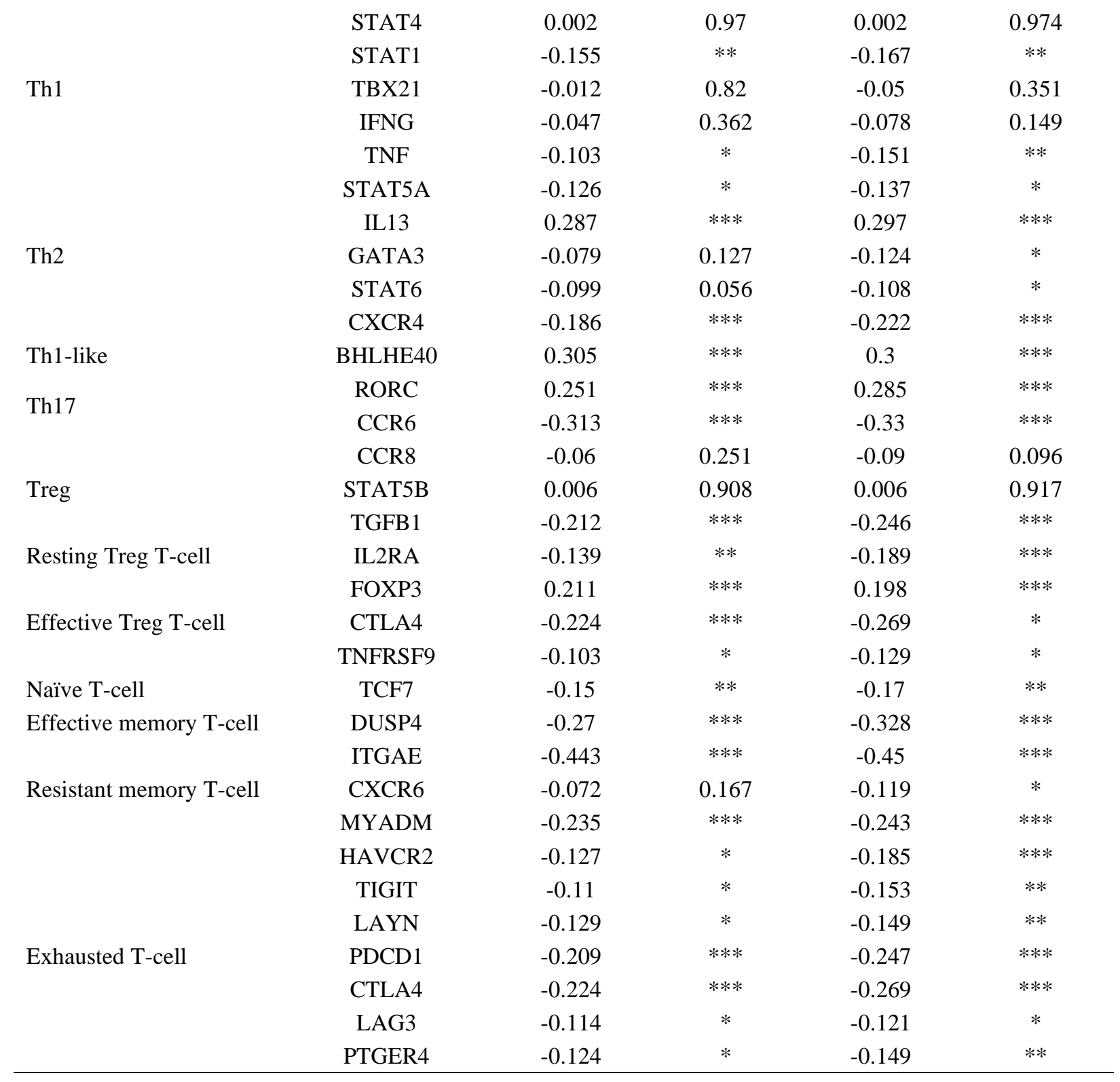

LIHC, Liver hepatocellular carcinoma. None, correlation without adjustment. Purity, correlation adjusted by purity. P-value: $0 \leq * * *<0.001 \leq * *<0.01 \leq *<0.05$. 